\title{
Interplay between PML NBs and HIRA for H3.3 deposition on transcriptionally active interferon-stimulated genes
}

Constance Kleijwegt ${ }^{1,2}$, Florent Bressac ${ }^{1}$, Camille Cohen ${ }^{1,3}$, Pascale Texier $^{1}$, Thomas Simonet ${ }^{4}$, Laurent Schaeffer ${ }^{4}$, Patrick Lomonte ${ }^{1, *}$ and Armelle Corpet ${ }^{1, *}$

1. Univ Lyon, Université Claude Bernard Lyon 1, CNRS UMR 5310, INSERM U 1217, LabEx DEVweCAN, Institut NeuroMyoGène (INMG), team Chromatin Dynamics, Nuclear Domains, Virus. F-69008, Lyon, France

2. Current address: Institute of Human Genetics, UMR9002 CNRS-Université de Montpellier, Laboratory of Biology of Repetitive Sequences, F-34000 Montpellier, France 3. Current address: Univ Montpellier, CNRS UMR 5235, Laboratory of Pathogen Host Interactions, F-34095, Montpellier, France.

4. Univ Lyon, Université Claude Bernard Lyon 1, CNRS UMR 5310, INSERM U 1217, Institut NeuroMyoGène (INMG), team Nerve-Muscle interactions. F-69008, Lyon, France

* To whom correspondence should be addressed.

Email : armelle.corpet@univ-lyon1.fr; patrick.lomonte@univ-lyon1.fr 


\begin{abstract}
Promyelocytic Leukemia Nuclear Bodies (PML NBs) are nuclear membrane-less organelles physically associated with chromatin underscoring their crucial role in genome function. The H3.3 histone chaperone complex HIRA accumulates in PML NBs upon senescence, viral infection or IFN-I treatment in primary cells. Yet, the molecular mechanisms of this partitioning and its function in regulating histone dynamics have remained elusive. Here, by using specific siRNAs and protein Affimers, we identify intermolecular SUMO-SIM interactions as an essential mechanism for HIRA recruitment in PML NBs. In addition, we demonstrate that HIRA localization in the nuclear bodies is intimately linked to the presence of a soluble pool of H3.3-H4 dimers inside PML NBs, that is not found in cancer cells. Transcription inhibition prevents HIRA accumulation in PML NBs underscoring the importance of transcriptional activity to drive HIRA through PML NBs. Finally, in the context of inflammatory responses, HIRA and PML are necessary for the prolonged H3.3 deposition at the transcriptional end sites of interferon-stimulated genes (ISGs), well beyond the peak of transcription. We thus propose that HIRA partitioning in PML NBs is essential to regulate H3.3 deposition on transcriptionally active regions.
\end{abstract}




\section{Introduction}

Eukaryotic nuclei constitute a crowded environment containing the densely packed genetic material together with all the biological macromolecules required to organize, replicate and interpret this genetic information. Promyelocytic Leukemia Nuclear Bodies (PML NBs) are membrane-less organelles, also called biomolecular condensates (1), that concentrate proteins at discrete sites within the nucleoplasm thus participating in the spatio-temporal control of biochemical reactions (2-4). In the majority of mammalian cell nuclei, PML NBs are found as $0.1-1 \mu \mathrm{m}$ diameter doughnut-shaped structures that vary in size and number depending on cell type, cell-cycle phase, or physiological state, highlighting their stress-responsive nature. The tumor-suppressor PML protein is the primary scaffold of PML NBs and forms an outer shell surrounding an inner core of dozens of proteins that localize constitutively or transiently in PML NBs (5). The PML gene was identified at the breakpoint of a common translocation $t(15,17)$ resulting in a PMLretinoic acid receptor alpha (RAR $\alpha$ ) fusion protein which disrupts PML NBs and drives acute promyelocytic leukemia (APL) (6).

PML (also known as TRIM19) is a member of the tripartite motif (TRIM)-containing protein superfamily characterized by a conserved RBCC motif. While several isoforms of PML exist, they all contain the N-terminal RBCC motif which is essential for PML polymerization and for recruitment of UBC9, the only SUMO E2-conjugating enzyme, driving NB formation. All PML isoforms contain three well-characterized small-ubiquitinrelated modifier (SUMO) modification sites at lysines K65, K160 and K490 of the PML primary sequence as well as a SUMO interacting motif (SIM) enabling it to interact with SUMOylated proteins $(3,7)$. UBC9-mediated SUMOylation of PML enforces PML-PML interactions via intermolecular SUMO-SIM interactions and drives the multivalent recruitment of inner core protein clients through their SIM possibly via liquid-liquid phase separation (LLPS) mechanisms $(3,4,8)$.

PML NBs have been involved in a wide variety of biological processes such as senescence, antiviral response, DNA damage response, or stemness suggesting that they are fully significant structures. However, the molecular mechanisms through which they exert their broad physiological impact are not fully elucidated yet. While PML NBs are mostly devoid of DNA, except in specific cases (for review (3)), they reside in the interchromatin nuclear space (9) and can associate with specific genomic loci (10-16). In particular, PML NBs have been found associated with both transcriptionally-permissive domains, as well as heterochromatin regions such as telomeres suggesting an important function in chromatin domain organization and regulation of their transcriptional state (for review (17)).

Targeted deposition of histones variants is crucial for chromatin homeostasis and the maintenance of cell identity (18). Among histone H3 variants, H3.3 is expressed throughout the cell cycle and is incorporated onto DNA in a DNA-synthesis independent manner by dedicated histone chaperone complexes (19). Histone cell cycle regulator A (HIRA) chaperone complex, composed of HIRA, ubinuclein 1 or ubinuclein 2 (UBN1 or UBN2) and calcineurin-binding protein CABIN1 is responsible for H3.3 deposition in transcriptionally active regions including enhancers, promoters and gene bodies, as well as in nucleosome-free regions and DNA damage sites $(20-23)$ (for review $(19,24)$ ). Antisilencing function 1A (ASF1A) is considered as an auxiliary component and delivers H3.3H4 dimers to the HIRA complex (25)(for review (24)). In contrast, the histone chaperone complex comprising death-domain associated protein (DAXX) and $\alpha$-thalassemia mental retardation syndrome X-linked (ATRX) targets H3.3 in specific heterochromatin regions such as telomeres, pericentromeric heterochromatin or endogenous retroviral 
sequences, and is required for H3.3-mediated deposition of H3 lysine 9 trimethylation (H3K9me3) to regulate transcriptional silencing $(15,22,26-29)$. In human somatic cells, a pool of neo-synthesized non-nucleosomal H3.3-H4 dimers is recruited to PML NBs by DAXX, which localizes constitutively in PML NBs together with ATRX, before deposition onto chromatin $(30,31)$, highlighting a key role of PML NBs in regulating the H3.3 chromatin assembly pathways $(16,30-32$ ) (for review (17)). While HIRA complex is diffusively distributed in the nuclei of proliferating somatic cells, it relocalizes in PML NBs upon various stresses such as senescence entry (33-36), a stable cell-cycle arrest playing an essential anti-tumoral role, viral infection with Herpes simplex virus 1 (HSV-1), a dsDNA containing virus (37-39), or interferon type I (IFN-I) treatment $(38,39)$. These latter events underscore a role of HIRA in intrinsic anti-viral defense via chromatinization of incoming viral genomes $(37,39)$ as well as stimulation of innate immune defenses in the case of viral infection (38).

However, the exact significance of HIRA localization in PML NBs upon stress response, as well as the role of the PML NBs themselves, remain unclear. PML NBs may both act as buffering/sequestration/degradation structures for various chromatin-related proteins, or may be a means to target them to specific chromatin regions juxtaposed to PML NBs. Here we investigated the molecular mechanisms of HIRA localization in PML NBs in primary cells. We show that HIRA localizes in PML NBs in a SIM-SUMO-dependent manner upon IFN-I treatment. In addition, we demonstrate that HIRA accumulation in PML NBs is intimately linked to the availability of H3.3-H4 dimers within PML NBs in primary cells but not cancer cells, and is connected with transcriptional activity. In context of the inflammatory transcriptional response, our ChIP-Seq analysis provides evidence for a long-lasting H3.3 deposition on the 3' end of interferon-stimulated genes (ISGs), which is dependent on HIRA and PML. Together, our results shed light on how a PML NBs-HIRAH3.3 axis helps to fine-tune H3.3 deposition during transcriptional activation. 


\section{Materials and Methods}

\section{Cell lines and lentiviruses production}

Human BJ primary foreskin fibroblasts (ATCC, CRL-2522), Human IMR90 fetal lung fibroblasts (ATCC, CCL-186), human HEK 293T embryonic kidney cells (Intercell, AG) and mouse MEFs embryonic fibroblasts $\mathrm{Pml}^{-/}$(from Dr. Lallemand-Breitenbach) were cultivated in DMEM medium (Sigma-Aldrich, D6429) containing 10\% of fetal calf serum (FCS) (Sigma-Aldrich, F7524), 1\% of penicillin/streptomycin (Sigma-Aldrich, P4458), at $37^{\circ} \mathrm{C}$ under $5 \% \mathrm{CO} 2$ and humid atmosphere.

Drugs and molecules used for cell treatments are described in Table 1 (duration is mentioned in the main text).

Table 1: Lists of drugs and molecules used in this study

\begin{tabular}{|l|l|l|}
\hline Name & Reference & Final concentration \\
\hline$\alpha$-amanitin & Sigma-Aldrich, A2263 & $2 \mu \mathrm{g} / \mathrm{mL}$ \\
\hline CDK9i (LDC067) & Sigma-Aldrich, SML2179 & $10 \mu \mathrm{M}$ \\
\hline Doxycycline & Sigma-Aldrich, D9891 & $100 \mathrm{ng} / \mathrm{mL}$ \\
\hline DRB & Sigma-Aldrich, D1916 & $50 \mu \mathrm{M}$ \\
\hline Flavopiridol & Euromedec, SE-S1230 & $50 \mathrm{nM}$ \\
\hline IFN $\beta$ (human, recombinant) & Peprotech, 300-02BC & $100 \mathrm{or} 1000 \mathrm{U} / \mathrm{mL}$ \\
\hline IFN $\alpha$ (mouse, recombinant) & $\begin{array}{l}\text { PBL assay science } \\
12105-1\end{array}$ & $1000 \mathrm{U} / \mathrm{mL}$ \\
\hline IL-6 (human, recombinant) & Peprotech, 200-06 & $200 \mathrm{ng} / \mathrm{mL}$ \\
\hline IL-8 (human, recombinant) & Peprotech, 200-08 & $200 \mathrm{ng} / \mathrm{mL}$ \\
\hline JQ1 & Sigma-Aldrich, SML1524 & $100-1000 \mathrm{nM}$ \\
\hline PolyI:C & Invivogen, tlrl-pic & $10 \mu \mathrm{g} / \mathrm{mL}$ \\
\hline Ruxolitinib & Invivogen, tlrl-rux & $2 \mu \mathrm{M}$ \\
\hline TNF $\alpha$ (human, recombinant) & Invivogen, rcyc-htnfa & $100 \mathrm{ng} / \mathrm{mL}$ \\
\hline
\end{tabular}

BJ, MEFs or IMR90 cells stably expressing transgenes were obtained by lentiviral transduction. Briefly, lentiviruses were produced in HEK 293T cells transfected by calcium-phosphate method with lentiviral plasmid containing the construct of interest, as well as psPAX.2 and pMD2.G packaging vectors in a 3:2:1 ratio. After $48 \mathrm{~h}$, the medium containing lentiviruses was filtered and applied on cells for transduction in complete medium containing polybrene at $8 \mu \mathrm{g} / \mathrm{mL}$ final concentration. Transduced cells were then selected $24 \mathrm{~h}$ later by adding the appropriate selective drug (puromycin (Invivogen, antpr) at $1 \mu \mathrm{g} / \mathrm{mL}$ or blasticidin (Invivogen, ant-bl) at $5 \mu \mathrm{g} / \mathrm{mL}$ )

\section{Plasmids}

Tat-S1S2D5-Flag-His Affimer (Tat: nuclear localization sequence), obtained by PCR using pcDNA5-Tat-S1S2D5-Flag-His as template (graciously sent by Dr. David J. Hughes (40)), was cloned in puromycin resistant pLVX-TetOne plasmid with BamHI and BstZ17I restriction enzymes.

HIRA WT, obtained by RT-PCR from HeLa cells, was cloned in blasticidin resistant pLentiN plasmid with EcoRI and XhoI restriction enzymes with addition of HA or Myc tag in the Cterminus. HIRA-HA mSIM and K809G mutants were obtained by site-directed mutagenesis using QuickChange Lightning Site-directed Mutagenesis kit (Agilent Technologies, \#210518). mSIM mutant sequences are the following: mSIM1: aa ${ }^{124} \mathrm{VSIL}^{127}$ mutated in ${ }^{124} \mathrm{GGIL}^{127}$, mSIM2: aa ${ }^{225} \mathrm{VLRL}^{228}$ mutated in ${ }^{225} \mathrm{GGRL}^{228}$, mSIM3: aa ${ }^{320} \mathrm{LLVI}^{323}$ 
mutated in ${ }^{320} \mathrm{GGVI}^{323}$, mSIM4: aa ${ }^{805} \mathrm{VVVV}^{808}$ mutated in ${ }^{805} \mathrm{GGVV}^{808}, \mathrm{mSIM} 5:$ aa ${ }^{978} \mathrm{VVGL}^{981}$ mutated in ${ }^{978} \mathrm{GGGL}^{981}$.

Myc-PML1 WT and 3K mutant, obtained by PCR using pLNGY-PML1 and pLNGYPML1.KKK as template (kind gift by Dr. Roger Everett), were cloned in puromycin resistant pLVX-TetOne plasmid with AgeI and BamHI restriction enzymes. H3.3-SNAPHA3 obtained by PCR using pBABE-H3.3-SNAP-HA3 as template (kind gift by Dr. Lars Jansen) was cloned into puromycin-resistant pLVX-TetOne plasmid with EcoRI restriction enzyme.

\section{SiRNAs}

BJ cells were transfected with $60 \mathrm{nM}$ of human siRNA for different timings (indicated in the main text for each experiment) using Lipofectamine RNAiMax reagent (Invitrogen, 13778-075) and Opti-MEM medium (Gibco, 31-985-070). siRNAs used and their sequences are summarized in Table 2. siSUMO-1 and siSUMO-2/3, were co-transfected into BJ cells at 30nM each.

Table 2: List of siRNAs and their sequences

\begin{tabular}{|l|l|l|}
\hline siRNA & Sequence & Reference \\
\hline siDAXX & 5'GGAGUUGGAUCUCUCAGAAdTdT & $\{$ Chen:2003fp $\}$ \\
\hline siHIRA & 5'GGAUAACACUGUCGUCAUCdTdT & $(21)$ \\
\hline siLuc & 5'CGUACGCGGAAUACUUCGAdTdT & $(41)$ \\
\hline siPML & 5'AGATGCAGCTGTATCCAAGdTdT & $(42)$ \\
\hline siSUMO-1 & 5'GGACAGGAUAGCAGUGAGAdTdT & $(43)$ \\
\hline siSUMO-2/3 & 5'GUCAAUGAGGCAGAUCAGAdTdT & $(44)$ \\
\hline siUBC9 & 5'GAAGUUUGCGCCCUCAUAAdTdT & $(45)$ \\
\hline
\end{tabular}

\section{Antibodies}

All the primary antibodies used in this study, together with the species, the reference and the dilutions for immunofluorescence and western blotting, are summarized in Table 3.

Table 3: List of primary antibodies

\begin{tabular}{|c|c|c|c|c|}
\hline \multirow{2}{*}{ Antibody } & \multirow{2}{*}{ Species } & \multirow{2}{*}{ Reference } & \multicolumn{2}{|c|}{ Dilution } \\
\hline & & & IF & WB \\
\hline Actin & $\begin{array}{l}\text { Rabbit } \\
\text { polyclonal }\end{array}$ & $\begin{array}{l}\text { Sigma-Aldrich } \\
\text { A2066 }\end{array}$ & & $1: 1000$ \\
\hline panH3 & $\begin{array}{l}\text { Rabbit } \\
\text { polyclonal }\end{array}$ & $\begin{array}{l}\text { Abcam } \\
\text { ab1791 }\end{array}$ & & $1: 5000$ \\
\hline H3.3 & $\begin{array}{l}\text { Rabbit } \\
\text { monoclonal }\end{array}$ & $\begin{array}{l}\text { Diagenode } \\
\text { C15210011 }\end{array}$ & & $1: 1000$ \\
\hline HA \#01 & $\begin{array}{l}\text { Rabbit } \\
\text { polyclonal }\end{array}$ & $\begin{array}{l}\text { Abcam } \\
\text { Ab9110 }\end{array}$ & 1:1000 & 1:1000 \\
\hline HIRA \#01 & $\begin{array}{l}\text { Mouse } \\
\text { monoclonal } \\
\text { (clone WC119) }\end{array}$ & $\begin{array}{l}\text { Active Motif } \\
3558\end{array}$ & $1: 500$ & $1: 1000$ \\
\hline HIRA \#02 & $\begin{array}{l}\text { Mouse } \\
\text { monoclonal } \\
(\text { clone WC119) }\end{array}$ & $\begin{array}{l}\text { Millipore } \\
04-1488\end{array}$ & $1: 500$ & $1: 1000$ \\
\hline $\begin{array}{l}\text { HIRA \#03 (for } \\
\text { mouse) }\end{array}$ & $\begin{array}{l}\text { Rabbit } \\
\text { polyclonal }\end{array}$ & $\begin{array}{l}\text { Abcam } \\
\text { ab20655 }\end{array}$ & $1: 100$ & \\
\hline
\end{tabular}




\begin{tabular}{|c|c|c|c|c|}
\hline $6 x H i s \# 01$ & $\begin{array}{l}\text { Mouse } \\
\text { monoclonal } \\
\text { (clone 3D5) } \\
\end{array}$ & $\begin{array}{l}\text { Clontech } \\
631212\end{array}$ & $1: 1000$ & \\
\hline $6 x H i s \# 02$ & $\begin{array}{l}\text { Rabbit } \\
\text { polyclonal }\end{array}$ & $\begin{array}{l}\text { Bethyl } \\
\text { A190-114A }\end{array}$ & $1: 10000$ & \\
\hline с-Мус \#01 & $\begin{array}{l}\text { Mouse } \\
\text { monoclonal } \\
\text { (clone 9E10) }\end{array}$ & $\begin{array}{l}\text { Santa Cruz } \\
\text { sc- } 40\end{array}$ & & $1: 1000$ \\
\hline c-Мус \#02 & $\begin{array}{l}\text { Rabbit } \\
\text { polyclonal }\end{array}$ & $\begin{array}{l}\text { Abcam } \\
\text { ab9106 }\end{array}$ & 1:1000 & \\
\hline PML \#01 & $\begin{array}{l}\text { Mouse } \\
\text { monoclonal } \\
\text { (clone PG-M3) }\end{array}$ & $\begin{array}{l}\text { Santa Cruz } \\
\text { sc-966 }\end{array}$ & $1: 200$ & \\
\hline PML \#02 & $\begin{array}{l}\text { Rabbit } \\
\text { polyclonal }\end{array}$ & $\begin{array}{l}\text { Santa Cruz } \\
\text { sc-5621 }\end{array}$ & $1: 200$ & $1: 1000$ \\
\hline PML \#03 & $\begin{array}{l}\text { Rabbit } \\
\text { polyclonal }\end{array}$ & $\begin{array}{l}\text { Sigma } \\
\text { PLA0172 }\end{array}$ & $1: 5000$ & $1: 1000$ \\
\hline $\begin{array}{l}\text { PML \#04 (for } \\
\text { mouse) }\end{array}$ & $\begin{array}{l}\text { Mouse } \\
\text { monoclonal } \\
\text { (clone 36.1- } \\
104 \text { ) }\end{array}$ & $\begin{array}{l}\text { Millipore } \\
\text { MAB3738 }\end{array}$ & $1: 100$ & \\
\hline SUMO-1 & $\begin{array}{l}\text { Rabbit } \\
\text { monoclonal } \\
\text { (clone Y299) } \\
\end{array}$ & $\begin{array}{l}\text { Abcam } \\
\text { ab32058 }\end{array}$ & & 1:1000 \\
\hline SUMO-2/3 & $\begin{array}{l}\text { Rabbit } \\
\text { polyclonal }\end{array}$ & $\begin{array}{l}\text { Abcam } \\
\text { ab3742 }\end{array}$ & & 1:1000 \\
\hline$\alpha$ Tubulin & $\begin{array}{l}\text { Mouse } \\
\text { monoclonal } \\
(\text { clone DM1A) }\end{array}$ & $\begin{array}{l}\text { Sigma } \\
\text { T6199 }\end{array}$ & & $1: 10000$ \\
\hline UBC9 & $\begin{array}{l}\text { Rabbit } \\
\text { polyclonal }\end{array}$ & $\begin{array}{l}\text { Abcam } \\
\text { ab33044 }\end{array}$ & & $1: 1000$ \\
\hline
\end{tabular}

\section{Immunofluorescence (IF)}

Cells were grown on glass coverslips. After treatments, cells were fixed in $2 \%$ paraformaldehyde (PFA) for 12 minutes at room temperature $\left(\mathrm{RT}^{\circ} \mathrm{C}\right)$. The cells were then permeabilized in PBS $0,2 \%$ Triton $\mathrm{X}-100$ for 5 minutes at $\mathrm{RT}^{\circ} \mathrm{C}$ and blocked in PBS $0,1 \%$ Tween (PBST) 5\% Bovine Serum Albumin (BSA) for 20 minutes at $\mathrm{RT}^{\circ} \mathrm{C}$. Cells were incubated in humid chamber with primary antibodies diluted in PBST 5\% BSA for 1 hour at $\mathrm{RT}^{\circ} \mathrm{C}$ or $\mathrm{O} / \mathrm{N}$ at $4^{\circ} \mathrm{C}$ (see Table 3 for antibodies dilution). After washing in PBST, cells were incubated with goat anti-mouse or anti-rabbit $(\mathrm{H}+\mathrm{L})$ cross-absorbed secondary antibodies Alexa-488, Alexa-555 or Alexa-647 (Invitrogen) diluted in PBST 5\% BSA in dark and humid chamber for 30 minutes at $\mathrm{RT}^{\circ} \mathrm{C}$. Cells were then incubated in DAPI (Invitrogen Life Technologies, D1306) diluted in PBS at $0,1 \mu \mathrm{g} / \mathrm{mL}$ for 5 minutes at $\mathrm{RT}^{\circ} \mathrm{C}$. Coverslips were mounted in Fluoromount-G (SouthernBiotech, 0100-01) and stored at $4^{\circ} \mathrm{C}$ before observation.

\section{Proximity Ligation Assay (PLA)}

Proximity Ligation Assays were performed with the Duolink In Situ Red Starter Kit Mouse/Rabbit (Sigma-Aldrich, DU092101). Cells on coverslips were fixed in 2\% PFA for 
12 minutes at $\mathrm{RT}^{\circ} \mathrm{C}$ and then permeabilized in PBS 0,2 \% Triton X-100 for 5 minutes at $\mathrm{RT}^{\circ} \mathrm{C}$. Cells were incubated in Duolink Blocking Solution for 1 hour at $37^{\circ} \mathrm{C}$ in humid chamber. Cells were then incubated in humid chamber with primary antibodies diluted in PBST $0,1 \%$ BSA for 1 hour at $\mathrm{RT}^{\circ} \mathrm{C}$ (see Table 3 for antibodies dilution). Cells were washed twice for 5 minutes in $1 \mathrm{X}$ Duolink Wash Buffer $\mathrm{A}$ at $\mathrm{RT}^{\circ} \mathrm{C}$ and then incubated in humid chamber for 1 hour at $37^{\circ} \mathrm{C}$ with PLUS and MINUS PLA probes diluted at 1:5 in the Duolink Antibody Diluent solution. After incubation, cells were washed twice for 5 minutes in $1 \mathrm{X}$ Duolink Wash Buffer A at $\mathrm{RT}^{\circ} \mathrm{C}$. Ligation step were then processed by incubating cells with the ligase diluted at 1:40 in $1 \mathrm{X}$ Duolink Ligation Buffer in humid chamber for 30 minutes at $37^{\circ} \mathrm{C}$. Cells were washed twice for 5 minutes in $1 \mathrm{X}$ Duolink Wash Buffer $\mathrm{A}$ ar $\mathrm{RT}^{\circ} \mathrm{C}$ before the amplification step where cells were incubated in a polymerase diluted at 1:80 in 1X Duolink Amplification Buffer in dark and humid chamber $\mathrm{O} / \mathrm{N}$ at $37^{\circ} \mathrm{C}$. Finally, cells were washed twice for 10 minutes in $1 \mathrm{X}$ Duolink Wash Buffer B and once for 1 minute in 0,01X Duolink Wash Buffer B at $\mathrm{RT}^{\circ} \mathrm{C}$. Coverslips were mounted in Duolink In Situ Mounting Medium with DAPI and stored at $4^{\circ} \mathrm{C}$ before observation.

\section{Microscopy, imaging, and quantification}

Images were acquired with the Axio Observer Z1 inverted wide-field epifluorescence microscope (100X or 63X objectives/N.A. 1.46 or 1.4) (Zeiss) and a CoolSnap HQ2 camera from Photometrics. Identical settings and contrast were applied for all images of the same experiment to allow data comparison. Raw images were treated with Fiji software or with Photoshop (Adobe). HIRA complex accumulation in PML NBs was attested by manual counting of a minimum of 100 cells for each condition. Quantification of nuclear HA fluorescence intensity was performed with Fiji. Briefly, DAPI staining was used to define masks of nuclei with the threshold and analyse particles functions. We then quantified mean HA fluorescence intensity within each nuclei with the measure function applied on the red (HA) channel.

\section{Western blotting (WB)}

Total cellular extracts were obtained by directly lysing the cells in $2 \mathrm{X}$ Laemmli sample buffer (LSB) (125 mM Tris-HCl pH 6.8, 20\% glycerol, 4\% SDS, bromophenol blue) containing $100 \mathrm{mM}$ DTT. RIPA extracts were obtained by lysing the cells in RIPA buffer (50mM Tris-HCl pH 7.5, 150mM NaCl, 0,5\% Na-Deoxycholate, 1\% NP-40, 0,1\% SDS, 5mM EDTA) supplemented with $1 \mathrm{X}$ protease inhibitor cocktail (PIC) for $20 \mathrm{~min}$ on ice. After incubation, RIPA extracts were centrifugated for $10 \mathrm{~min}$ at $16000 \mathrm{~g}$ at $4^{\circ} \mathrm{C}$ and supernatants were recovered and diluted with 4X LSB $(250 \mathrm{mM}$ Tris- $\mathrm{HCl} \mathrm{pH} 6.8,40 \%$ glycerol, 8\% SDS, bromophenol blue).

Protein extracts were boiled for 10 minutes and then loaded on polyacrylamide gels (TGX Stain-Free FastCast gels (Bio-Rad, 1610181/1610183) or home-made gels) for electrophoresis. Ponceau 0,1\% (Sigma-Aldrich, P7170) were used to reveal proteins transferred on nitrocellulose membrane with the Trans-Blot Turbo Transfer System (BioRad, 1704150). Membranes were blocked in PBST 5\% milk for 30 minutes at $\mathrm{RT}^{\circ} \mathrm{C}$ and incubated with primary antibodies diluted in PBST 0/N at $4^{\circ} \mathrm{C}$ (see Table 3 for antibodies dilution). After washing the membranes thrice in PBST, they were incubated in secondary antibodies conjugated with horseradish peroxidase (HRP) (Dako, P0399, P0447 and P0450) diluted according to supplier recommendations in PBST for 1 hour at $\mathrm{RT}^{\circ} \mathrm{C}$. Signal was revealed on ChemiDoc Imaging System (Bio-Rad) by using Amersham ECL Prime Western Blotting Detection Reagent (GE Healthcare Life Sciences, RPN2236) or Clarity Max Western ECL Blotting Substrate (Bio-Rad, 1705062). 


\section{Chromatin immunoprecipitation (ChIP)}

Cells were crosslinked directly in the culture dishes by adding fixing solution (11\% formaldehyde, $50 \mathrm{mM}$ HEPES-KOH pH 7.5, $100 \mathrm{mM} \mathrm{NaCl}, 1 \mathrm{mM}$ EDTA, 0,5mM EGTA) to the medium to have $1 \%$ formaldehyde final concentration and incubated with agitation for 5 minutes at $\mathrm{RT}^{\circ} \mathrm{C}$. Crosslinking was quenched by adding $125 \mathrm{mM}$ glycine and cells were incubated with agitation for 5 minutes at $\mathrm{RT}^{\circ} \mathrm{C}$. Cells were washed with ice-cold PBS, scraped and collected in $15 \mathrm{~mL}$ tubes. They were washed twice with ice-cold PBS and pelleted at $200 \mathrm{~g}$ for 4 minutes at $4^{\circ} \mathrm{C}$. Cell pellets were snap-frozen in liquid nitrogen and stored at $-80^{\circ} \mathrm{C}$ before immunoprecipitation.

Cells were de-frozen on ice and lysed in $1 \mathrm{X}$ Lysis buffer (50mM HEPES-KOH pH 7.5, $140 \mathrm{mM} \mathrm{NaCl}, 10 \%$ Glycerol, $1 \mathrm{mM}$ EDTA, 0,5\% NP-40, 0,25\% Triton X-100) supplemented with protease inhibitors $(0,2 \mathrm{mM}$ PMSF and $1 \mathrm{X}$ PIC) for 10 minutes on atating wheel at $4^{\circ} \mathrm{C}$. Intact nuclei were pelleted by centrifugation at $1700 \mathrm{~g}$ for 5 minutes at $4^{\circ} \mathrm{C}$. Nuclei were washed with $1 \mathrm{X}$ Wash buffer $(10 \mathrm{mM}$ Tris- $\mathrm{HCl} \mathrm{pH} 8.0,200 \mathrm{mM} \mathrm{NaCl}, 1 \mathrm{mM}$ EDTA, $0,5 \mathrm{mM}$ EGTA) supplemented with protease inhibitors for 10 minutes on a rotating wheel at $4^{\circ} \mathrm{C}$. Intact nuclei were pelleted by centrifugation at $1700 \mathrm{~g}$ for 5 minutes at $4^{\circ} \mathrm{C}$. Nuclei were washed twice in $1 \mathrm{X}$ Shearing buffer (10mM Tris-HCl pH 8.0, 1mM EDTA, 0,1\% SDS) supplemented with protease inhibitors, pelleted by centrifugation at $1700 \mathrm{~g}$ for 5 minutes at $4^{\circ} \mathrm{C}$ and resuspended in $1 \mathrm{X}$ Shearing buffer with inhibitors for sonication. We used the Covaris M220 Focused-ultrasonicator to shear through chromatin (7 minutes at 140W, Duty off $10 \%$, Burst cycles 200). After shearing, samples were supplemented with $1 \%$ Triton X-100 and $150 \mathrm{mM} \mathrm{NaCl}$. Samples were centrifuged at maximal speed for 10 minutes at $4{ }^{\circ} \mathrm{C}$ to get rid of nuclear debris. The desired mass of chromatin was aliquoted into low-retention 1,5mL tubes (Axygen, MCT-150-L-C) and volume was completed to $1 \mathrm{~mL}$ with IP buffer (10mM Tris-HCl pH 8.0, 150mM NaCl, 1mM EDTA, 0,1\% SDS, 1\% Triton X-100) with protease inhibitors. A separate aliquot of chromatin was reserved as the input sample and store at $-20^{\circ} \mathrm{C}$.

Dynabeads protein A magnetic beads (Invitrogen, 10001D) were used for immunoprecipitation with rabbit primary antibodies. Dynabeads were washed twice with ice-cold PBS and resuspended in PBS 0,5\% BSA supplemented with primary antibodies (anti-H3.3 (Diagenode, C15210011), anti-panH3 (Abcam, ab1791), rabbit IgG (Diagenode, C15410206)). We used $2 \mu \mathrm{g}$ of antibody for $20 \mu \mathrm{L}$ of dynabeads. Dynabeads and antibodies were incubated on a rotating wheel for 6 hours at $4^{\circ} \mathrm{C}$ to allow antibody conjugation. Antibody-conjugated dynabeads were then washed twice with IP buffer and resuspended in the $1 \mathrm{~mL}$ of chromatin. ChIP samples were incubated on a rotating wheel $\mathrm{O} / \mathrm{N}$ at $4^{\circ} \mathrm{C}$.

Using a magnetic rack, the unbound lysates were aspirated and dynabeads were washed five times with ice-cold ChIP RIPA Buffer (50mM HEPES pH 7.5, 500mM LiCl, 1mM EDTA, $1 \%$ NP-40, 0,7\% Na-deoxycholate) and once with ice-cold TE buffer (10mM Tris-HCl pH 8.0, 1 mM EDTA). Chromatin was then eluted in 200uL of ChIP Elution buffer (Tris-HCl pH 8.0, $10 \mathrm{mM}$ EDTA, $1 \%$ SDS) for 30 minutes at $65^{\circ} \mathrm{C}$ with shaking and the eluates were transferred to a new tube. Reserved input samples were diluted at least 3-fold in ChIP Elution buffer. To purify DNA, ChIP eluates and input samples were decrosslinked by heating $0 / \mathrm{N}$ at $65^{\circ} \mathrm{C}$. Samples were diluted with $200 \mu \mathrm{L}$ of TE buffer and treated for 2 hours with RNase A $(200 \mu \mathrm{g} / \mathrm{mL})$ (SIGMA R6513) at $37^{\circ} \mathrm{C}$ followed by 2 hours with recombinant Proteinase K $(200 \mu \mathrm{g} / \mathrm{mL})$ (Thermo Scientific, 10181030$)$ at $55^{\circ} \mathrm{C}$. DNA was purified by phenol-chloroform-isoamyl alcohol extraction. The extracted aqueous phase was supplemented with $200 \mathrm{mM}$ of $\mathrm{NaCl}$ and $20 \mu \mathrm{g}$ of glycogen. DNA was precipitated with 
EtOH for 2 hours at $-20^{\circ} \mathrm{C}$ and pelleted at $20000 \mathrm{~g}$ for 20 minutes at $4^{\circ} \mathrm{C}$. DNA pellets were resuspended in $\mathrm{ddH} 20$ and stored at $-20^{\circ} \mathrm{C}$ before qPCR analysis.

\section{Reverse Transcription (RT)}

TRIzol reagent protocol (Invitrogen, 15596026) was used to isolate total RNAs, resuspended in ddH2O according to the manufacturer instructions. Contaminant DNA was removed with the DNA-free DNA Removal Kit (Invitrogen, AM1906). We used $1 \mu \mathrm{g}$ of RNA for reverse transcription (RT). RNAs were annealed with Random Primers (Promega, C118A) and RT was performed with the RevertAid H Minus Reverse Transcriptase (Thermo Scientific, EP0452) according to the manufacturer instructions. cDNAs were stored at $-20^{\circ} \mathrm{C}$ before qPCR analysis.

\section{Quantitative PCR (qPCR)}

qPCRs were performed using the KAPA SYBR qPCR Master Mix (SYBR Green I dye chemistry) (KAPA BIOSYSTEMS, KK4618). Primers used for qPCR are described in Table 4.

Table 4: List of primers used for qPCR

\begin{tabular}{|c|c|c|c|}
\hline Name & $\begin{array}{l}\text { Forward primers } \\
\left(5^{\prime} \rightarrow 3^{\prime}\right)\end{array}$ & $\begin{array}{l}\text { Reverse primers } \\
\left(5^{\prime} \rightarrow 3^{\prime}\right)\end{array}$ & Ref \\
\hline \multicolumn{4}{|l|}{ ChIP qPCR } \\
\hline $\begin{array}{l}\text { H3.3-ChIP- } \\
\text { cluster3-Chr1 }\end{array}$ & $\begin{array}{l}\text { GCC-ACT-TGC-CAA- } \\
\text { TGT-TTC-TC }\end{array}$ & $\begin{array}{l}\text { TGG-CCC-CAT-GTA-GTG- } \\
\text { AAA-AG }\end{array}$ & $(46)$ \\
\hline ChIP-MX1-TSS & $\begin{array}{l}\text { GGG-ACA-GGC-ATC- } \\
\text { AAC-AAA-GCC }\end{array}$ & $\begin{array}{l}\text { GCC-CTC-TCT-TCT-TCC- } \\
\text { AGG-CAA-C }\end{array}$ & (47) \\
\hline ChIP-MX1-mid & $\begin{array}{l}\text { TCT-ACG-CTC-TGG- } \\
\text { GGA-CAT-CA }\end{array}$ & $\begin{array}{l}\text { GAA-CCA-AAC-CCA-CCA- } \\
\text { CCA-GA }\end{array}$ & \\
\hline ChIP-MX1-TES & $\begin{array}{l}\text { CTC-CCG-TGA-ACT- } \\
\text { GTT-CTT-TCC-T }\end{array}$ & $\begin{array}{l}\text { GCT-GTA-GGT-GTC-CTT- } \\
\text { GTC-CT }\end{array}$ & \\
\hline ChIP-OAS1-TSS & $\begin{array}{l}\text { ACC-ACA-GAC-AAC- } \\
\text { TGT-GAA-AGG }\end{array}$ & $\begin{array}{l}\text { GTC-CTT-TAG-CCA-GCA- } \\
\text { ACA-AGC }\end{array}$ & \\
\hline ChIP-OAS1-mid & $\begin{array}{l}\text { GCA-GCA-CGT-TGG- } \\
\text { GAG-ATA-GA }\end{array}$ & $\begin{array}{l}\text { TTC-TCC-TGA-TGT-GGC- } \\
\text { AAG-GG }\end{array}$ & \\
\hline ChIP-OAS1-TES & $\begin{array}{l}\text { CTT-GTC-ACA-TCC- } \\
\text { CCA-CCT-CTC }\end{array}$ & $\begin{array}{l}\text { GTC-CTT-TGC-CCC-TGT- } \\
\text { TTA-GC }\end{array}$ & \\
\hline $\begin{array}{l}\text { ChIP-ISG54- } \\
\text { TSS }\end{array}$ & $\begin{array}{l}\text { GCA-GGA-AGT-GGG- } \\
\text { GTT-TGC-TA }\end{array}$ & $\begin{array}{l}\text { GAG-GGA-TGT-TTC-ATC- } \\
\text { GGC-CT }\end{array}$ & \\
\hline $\begin{array}{l}\text { ChIP-ISG54- } \\
\text { mid }\end{array}$ & $\begin{array}{l}\text { ATG-TAA-CTA-ACC- } \\
\text { CCA-GGT-GCG }\end{array}$ & $\begin{array}{l}\text { TGC-TTC-CCA-CTC-CCA- } \\
\text { TTT-TGA }\end{array}$ & \\
\hline $\begin{array}{l}\text { ChIP-ISG54- } \\
\text { TES }\end{array}$ & $\begin{array}{l}\text { AGT-CTG-GAA-GCC- } \\
\text { TCA-TCC-CT }\end{array}$ & $\begin{array}{l}\text { CCT-AGT-GGG-CAC-CAC- } \\
\text { ATC-TC }\end{array}$ & \\
\hline \multicolumn{4}{|l|}{ RT qPCR } \\
\hline$G A P D H$ & $\begin{array}{l}\text { GAG-TCA-ACG-GAT- } \\
\text { TTG-GTC-GT }\end{array}$ & $\begin{array}{l}\text { TTG-ATT-TTG-GAG-GGA- } \\
\text { TCT-CG }\end{array}$ & \\
\hline ISG15 & $\begin{array}{l}\text { GGT-GGA-CAA-ATG- } \\
\text { CGA-CGA-AC }\end{array}$ & $\begin{array}{l}\text { TCG-AAG-GTC-AGC-CAG- } \\
\text { AAC-AG }\end{array}$ & \\
\hline
\end{tabular}




\begin{tabular}{|l|l|l|l|}
\hline \multirow{2}{*}{ ISG54 } & $\begin{array}{l}\text { TGA-AAG-AGC-GAA- } \\
\text { GGT-GTG-CT }\end{array}$ & $\begin{array}{l}\text { CTC-AGA-GGG-TCA-ATG- } \\
\text { GCG-TT }\end{array}$ & \\
\hline \multirow{2}{*}{ MX1 } & GGA-GGC-ACT-GTC- & $\begin{array}{l}\text { TCC-TGG-TAA-CTG-ACC- } \\
\text { TTG-CC }\end{array}$ & \\
\hline \multirow{2}{*}{ OAS1 } & AGG-AGT-TG & AGC-TGG-AAG-CCT- & AGG-TTT-ATA-GCC-GCC- \\
& GTC-AAA-GA & AGT-CAA & \\
\hline
\end{tabular}

\section{ChIP-Seq analysis}

After ChIP, libraries were made in BGI and sequenced on a BGISEQ-500 sequencing platform (https://www.bgi.com). An average of 34 Million single-end 50bp reads was obtained for each library. Reads were trimmed using Trimmomatic and quality assessed with FastQC. Reads were aligned to the human genome hg38 using the BWA alignment software. Duplicate reads were identified using the picard tools script and only nonduplicate reads were retained. Broad peaks calling was performed with MACS2 (48) ("-extsize 250 -q 0.01 --broad --broad-cutoff 0.05"), using input DNA as control. We defined all possible locations of $\mathrm{H} 3.3$ by merging broad peaks identified in our four conditions ( $\mathrm{n}=190295)$, and them with Homer (http://homer.ucsd.edu/homer/download.html ). We counted reads extended to 250bp falling into these possible locations, in the four ChIP and their corresponding inputs, using bedtools-intersect. CPMs were obtained by dividing raw counts by the total number of mapped reads normalized to $1 \mathrm{e} 6$, and RPKMs by dividing CPMs by the peak length normalized to 1e3. Input RPKMs, used as background, was substracted from the respective ChIP RPKMs. We focused on $0,5 \%$ of the peaks with highest RPKM difference $(n=951)$ between IFN $\beta$ treated and not treated conditions, of which 711 were intragenic. These peaks allowed us to defined a set of 654 genes, on which we performed GO analysis, with MsigDB, using enrichR plaform (49).

As a complementary approach, we measured the ChIP enrichment within the $1000 \mathrm{bp}$ regions spanning the TESs $(-500+500)$, extending all unique reads into $250 \mathrm{bp}$ fragments, and counting those falling within TES using bedtools-intersect. CPMs were obtained similarly, and input DNA CPMs, used as background, was substracted from ChIP CPMs. Genes with the log 2 of differential TES enrichment between IFN $\beta$ treated and not treated conditions being higher than 5 ( $\log 2$ (Fold Change) $>5$ ) were retained for GO analysis, as described above.

PlotProfile were generated using the DeepTools suite, starting from the MACS2 fold enrichment bigwig files, which take into account the read extension, the input DNA background and the library size normalization. The list of 48 core ISGs and 48 non-ISGs equal in size to the core ISGs was taken from (38). In order to reduce the noise on the profiles, we selected for each gene the transcript with the highest H3.3 enrichment at the TES in the IFN $\beta$ treated condition. Genome browser snapshots of H3.3 enrichment were generated using Integrative Genomics viewer (IGV : https://software.broadinstitute.org/software/igv/).

\section{Statistical analyses}

Statistical analyses were performed using GraphPad Prism 6. To perform Student t test, we verified normal distribution of samples using Shapiro test and variance equality with Fisher test. Mann-Whitney u-test was applied in absence of normality for the sample distribution. p-values are depicted on graphs as follows : ${ }^{*}<0,05 ;{ }^{* *}<0,01 ;{ }^{* * *}<0,001$; $* * * *<0,0001$. 


\section{Results}

\section{HIRA accumulation in PML NBs correlates with an increase in PML valency}

While several stimuli such as senescence (33-36), infection with a dsDNA virus (37-39) or interferon type I (IFN-I) treatment $(38,39)$ can trigger HIRA accumulation in PML NBs, little is known about the molecular mechanisms responsible for its recruitment in PML NBs. PML NBs contain multiple chromatin-associated factors whose localization is regulated via a switch-like partitioning between the diffuse nucleoplasmic phase and the condensed PML NB phase $(3,50)$. Previous studies suggest that a valency-dependent partitioning of a given client protein is controlled by the multivalent interactions between its SIM motifs and SUMOylated lysines on the PML protein, as shown for DAXX $(8,50)$. Thus, as a first step towards dissection of the mechanism of HIRA localization in PML NBs, we sought to investigate whether HIRA recruitment in these nuclear bodies depends on an increase in PML valency.

Treatment of human primary foreskin diploid fibroblast BJ cells with the TLR3 ligand poly(I:C), a synthetic analog of double-stranded RNA which is a strong stimulant of the IFN-I pathway, or with the pro-inflammatory Tumor necrosis factor $\alpha$ (TNF $\alpha$ ) cytokine, triggered a strong accumulation of HIRA in PML NBs (Figures 1A-B), as observed with a control IFN-I treatment (Sup. Figure 1A). This accumulation was abrogated by addition of ruxolitinib, an inhibitor of the JAK-STAT pathway downstream of the IFN-I receptor, underscoring a dependency on the IFN-I signaling pathway in BJ cells (Figures 1A-B and Sup. Figure 1A). Interestingly, both IFN $\beta$, poly(I:C) and TNF $\alpha$ increased the levels of the PML protein and its SUMOylated forms in an IFN-I dependent manner as seen by western blot analysis (Figure 1C), confirming the known increase of PML protein levels and SUMOylation induced by IFN-I (51) and TNF $\alpha$ (52). In contrast, treatment of BJ cells with other pro-inflammatory cytokines such as IL- 6 or the IL-8 chemokine, which did not increase PML protein levels or SUMOylation (Sup. Figure 1B), did not affect HIRA localization that remained pan-nuclear (Sup. figure 1C). Thus, our results suggest that an IFN-I-dependent increase of PML valency (increase in protein levels and SUMOylation), is part of the mechanism for HIRA accumulation in PML NBs.

\section{Accumulation of HIRA in PML NBs depends on SUMOylated PML}

We thus hypothesize that HIRA's partitioning in PML NBs may be regulated by SUMO-SIM interactions. We first investigated whether HIRA and PML/SUMO could interact together in cellulo. We used Proximity Labelling Assay (PLA) which allows the detection of closely interacting protein partners in situ at distances below 40nm (53). Using PLA, we detected interaction foci between PML and SUMO2/3 as expected (53), and the number of interaction foci increased significantly upon IFN $\beta$ treatment (Figures 2A-B), which is known to stimulate PML SUMOylation (54). We then applied PLA to assess interactions between HIRA and PML or HIRA and SUMO2/3. In presence of IFN $\beta$, we could detect a significant interaction between these proteins (Figures 2A-B), a condition under which HIRA accumulates in PML NBs. Positive PLA signal between HIRA and SUMO2/3 could either mean that HIRA is SUMOylated or that HIRA interacts with other SUMOylated proteins. However, the molecular mass of HIRA remained unchanged upon IFN $\beta$ treatment of BJ cells (Sup. Figure 1E), as previously described (38), which is not in favor of post-translational modification of HIRA with SUMO groups. We thus conclude that HIRA interacts with SUMOylated PML in situ.

To confirm that SUMOylation of cellular proteins, including PML, is required for HIRA partitioning in PML NBs, we depleted the pool of SUM01/2/3 by siRNA treatment, which led to the disappearance of most SUMOylated proteins in cells (Figure 2C). Depletion of 
SUM01/2/3 led to a significant decrease of HIRA accumulation in PML NBs upon IFN $\beta$ treatment (Figure 2D). Of note, in absence of SUMO, PML NBs appear as large aggregates devoid of DAXX (Sup. Figure 2A), reminiscent of the alternative PML NBs structures observed during mitosis, in human embryonic stem cells or sensory neurons (3). Thus, presence of SUMO proteins, that can undergo LLPS in vitro $(40,50)$, seems key to promote partitioning of HIRA. Depletion of UBC9, the only known E2 SUMO conjugating enzyme in mammalian cells did not impair HIRA accumulation (Sup. Figure 2B-C)(38) nor DAXX localization in PML NBs (Sup. Figure 2A) underscoring the importance of removing the whole pool of soluble SUMO proteins to impact on client recruitment and suggesting that the steady state SUMOylation levels are not sufficiently impacted by UBC9 depletion. On the contrary, increasing the pool of free SUMO proteins by ectopic expression did not trigger HIRA accumulation in PML NBs (Sup. Figure 2D) suggesting that SUMO proteins need to be conjugated to specific proteins to trigger HIRA partitioning in PML NBs.

To further substantiate the requirements for non-covalent SUMO/SIM interactions in mediating HIRA accumulation in PML NBs, we used the Affimer technology, previously known as Adhiron. Affimers are artificial protein aptamers consisting of a scaffold with two variable peptide presentation loops that can specifically bind with high affinity and high specificity to their binding partners. A recent screen identified several Affimers that inhibit SUMO-dependent protein-protein interactions mediated by SIM motifs (40). We selected the S1S2D5 Affimer that specifically targets both SUMO1 and SUMO2/3mediated interactions and possesses a consensus SIM motif (40). We first verified the expression of the S1S2D5 Affimer from inducible 6xHis-tagged S1S2D5 Affimerexpressing BJ cells. S1S2D5-His Affimer showed a nuclear staining with accumulation of the Affimer in PML NBs as expected for a synthetic peptide that exhibits a SIM domain (40, 50) (Figures 3A-B). In conditions where the S1S2D5-His Affimer was expressed, we found that the accumulation of HIRA in PML NBs upon IFN $\beta$ stimulation treatment was greatly impaired, as shown by immunfluorescence quantification (Figure 3C). Importantly, SUMO-specific Affimers did not affect HIRA nor PML levels as verified by western Blot (Sup. Figure 2E). In addition, they do not prevent in vivo conjugation of SUMO by UBC9 (40) corroborating our results (Sup. Figures 2A-C) and those of McFarlane (38) in the nonessential role of UBC9 in regulating HIRA partitioning. Collectively, our results demonstrate that SUMO/SIM interactions play an important role in the targeting of HIRA in PML NBs in response to IFN $\beta$.

PML is known to be mainly SUMOylated on three major lysines K65, K160 and K490 (7). We took advantage of immortalized Pml-/- mouse embryonic fibroblasts (MEFs) reconstituted with a doxycyclin-inducible wild-type Myc-tagged version of human PML (Myc-PML WT) or a PML mutated on its three main SUMOylation sites (Myc-PML 3K) to investigate the specific requirements for PML SUMOylation in HIRA partitioning (Figure 3D). Of note, super resolution microscopy analyses of these MEFs reveal that PML 3K form spherical structures exactly like WT PML (8). In addition, we also verified that HIRA localization in PML NBs was conserved in wild-type MEFs upon treatment with a mouse IFN $\alpha$ and was lost in Pml-/- MEFs (Sup. Figure 2F). Upon doxycyclin induction, Myc-PML WT or its mutated form were expressed at high levels in Pml-/- MEFs, although addition of mouse IFN $\alpha$ lowered the expression levels of the tagged PML proteins (Figure 3D). Nevertheless, presence of the wild type exogenous tagged PML protein rescued HIRA accumulation in PML NBs upon IFN $\alpha$ addition while presence of the $3 \mathrm{~K}$ mutated form of PML prevented it (Figure 3E). These data demonstrate that PML SUMOylation on K65, K160 and K490 is required for HIRA recruitment in PML NBs. Multivalent interactions between client SIM motifs and SUMOylated lysines on the PML protein are implicated in 
client recruitment in PML NBs, as shown for DAXX $(8,50)$. Using JASSA (55) and GPSSUMO (56), we selected a set of 5 putative SIM motifs in HIRA protein sequence and tested whether they were involved in HIRA recruitment in PML NBs. BJ cells expressing the wildtype (WT) tagged version of HIRA (HIRA-HA WT) displayed ectopic HIRA accumulation in PML NBs upon IFN $\beta$ treatment (Figure 3F). While mSIM1 and mSIM3 mutants did not show sufficient expression to allow interpretation of their localization, none of the mSIM4 and mSIM5 HIRA-HA mutants showed any defects in the accumulation in PML NBs (Sup. Figure 2G). In contrast, the HIRA-HA mSIM2 showed an impaired accumulation in PML NBs upon IFN $\beta$ treatment (Figure 3F). Although the number of cells expressing HIRA-HA mSIM2 remained rather low, precluding any biochemical analyses, we could clearly monitor from numerous individual cells a significant decrease of HIRA-HA mSIM2 mutant in PML NBs upon IFN $\beta$ stimulation (Figure 3F), suggesting the importance of this putative SIM in HIRA recruitment within PML NBs. Thus, we conclude that HIRA accumulation in PML NBs following activation of the IFN-I signaling pathway is dependent on interaction between SUMOylated PML and HIRA via a putative SIM motif.

\section{Soluble H3.3 pool regulates HIRA accumulation in PML NBs}

HIRA does not localize in PML NBs in cancer cells such as HeLa or U2OS (Sup. Figure 3A) $(38,39)$ despite a similar increase in SUMOylated PML upon IFN-I treatment as seen by western blot analysis (Sup. Figure 3B). We thus focused our attention on understanding whether other molecular mechanisms might govern HIRA localization in PML NBs. From the above data, neither the increase in PML valency, nor free SUMOs pool, seem sufficient to trigger HIRA accumulation in PML NBs. Remarkably, PML NBs have a strong connection with the H3.3 chromatin assembly pathway. Soluble newly synthesized H3.3-H4 dimers localize in PML NBs in a DAXX-dependent manner in human primary cells, before deposition onto chromatin $(30,31)$. PML NBs may thus function as triage centers for the sorting of soluble H3.3-H4 dimers among various histone chaperones which could then be released for incorporation of H3.3-H4 into chromatin $(3,30,31)$.

We tested whether altering the pool of soluble neosynthesized H3.3-H4 dimers available could perturb HIRA localization in primary cells in an IFN-I independent manner. For this, we first analyzed HIRA localization in BJ cells in absence of DAXX, which impairs recruitment of soluble neosynthesized H3.3-H4 dimers in PML NBs $(30,31)$. DAXX knockdown by siRNA led to a significant increase in the proportion of cells showing HIRA accumulation in PML NBs (Figure 4A), which remained visible in cells treated with ruxolitinib (Figure 4A), ruling-out a possible contribution of the IFN-I signaling pathway for this specific accumulation of HIRA in PML NBs. In addition, no significant increase for PML protein was observed upon DAXX siRNA treatment (Figure 4B and Sup. Figure 3C). This suggests that in absence of its H3.3-H4 cargo, HIRA may accumulate in PML NBs without major changes in PML valency.

We then hypothesized that HIRA complex could localize in PML NBs in order to retrieve H3.3-H4 dimers concentrated in PML NBs. If so, we anticipated that the overexpression of soluble H3.3-H4 dimers should bypass the requirement of HIRA localization in PML NBs following IFN-I stimulus. We thus generated human primary BJ cells expressing an inducible HA-tagged form of H3.3 (BJ eH3.3i). Treatment with doxycyclin triggered a strong, yet highly variable, expression of eH3.3 (Figures 4C-E), consistent with the polyclonal nature of the BJ eH3.3i. Also, eH3.3 was only detectable in PML NBs in lowexpressing cells (Figures 4D, F and Sup. Figure 3D).

BJ eH3.3i cells were then treated with IFN $\beta$ to trigger HIRA accumulation in PML NBs and concomitantly with doxycyclin, to induce overexpression of eH3.3, respectively. We 
verified that doxycyclin did not impact HIRA localization in absence of IFN $\beta$. Addition of IFN $\beta$ alone triggered a normal increase in the number of BJ eH3.3i cells showing accumulation of HIRA in PML NBs (Figure 4C). Strikingly, we observed that this accumulation of HIRA in PML NBs was impaired following IFN $\beta$ treatment in cells with strong expression of eH3.3 (Figures 4C-D). In contrast, low eH3.3-expressing cells did not show any significant modification of the behavior of HIRA, which was detected in PML NBs together with eH3.3 (Figures 4C-D). In order to quantify this effect, we plotted the mean eH3.3 nuclear fluorescence intensity in BJ eH3.3i cells treated with doxycyclin together with IFN $\beta$ (Figures 4D-E). In nuclei showing accumulation of HIRA in PML NBs together with eH3.3, the eH3.3 nuclear intensity was low in average. In contrast, in nuclei showing absence of HIRA in PML NBs, a significant shift to higher eH3.3 nuclear intensities was observed underscoring a strong antagonism between HIRA detection in PML NBs and high expression of eH3.3 (Figures 4D-E). Among the cells showing HIRA in PML NBs, only $9.2 \%$ of them were high eH3.3-expressing cells, i.e. with a mean H3.3-HA nuclear intensity higher than the one of $75 \%$ of the total cells. Similar results were obtained in human primary lung fibroblasts in which most cells showing accumulation of HIRA in PML NBs expressed low or very low eH3.3, which was detectable in PML NBs (Figure 4F). On the contrary, massive pool of soluble H3.3 in the nucleoplasm correlated with the absence of detection of HIRA in PML NBs.

Noteworthy, we could not detect eH3.3 in PML NBs in HeLa cells expressing the same doxycyclin-inducible epitope-tagged H3.3-HA (Sup. Figure 3E), confirming previous results using the SNAP tag (21). This raises the possibility that HIRA accumulation in PML NBs may be lost in cancer cells due to the absence of H3.3-H4 dimers in PML NBs in these cells. Collectively, our results establish that availability of soluble H3.3-H4 dimers in PML NBs is a crucial parameter governing HIRA accumulation in these nuclear bodies.

\section{Transcription inhibition prevents HIRA accumulation in PML NBs}

After having determined essential molecular parameters leading to the partitioning of HIRA in the PML NBs, we investigated whether this could be linked to the role of the HIRA complex as an H3.3 chaperone during transcription. The HIRA complex is enriched in transcriptionally active regions and can interact both with RNA polymerase II or with RPA-bound regions of nucleosome-free DNA providing a means to mediate H3.3 deposition coupled to transcription $(21,23,46,57)$. Also, HIRA has been recently shown to be involved in the transcription-mediated recycling of parental H3.3 (58). Moreover, PML NBs are frequently found in regions of high transcriptional activity $(9,11,12)$.

We therefore assessed HIRA localization relative to PML NBs with various transcriptional inhibitors in IFN $\beta$-treated cells. Treatment of cells with DRB, a general transcription inhibitor that inhibits CDK9, the kinase subunit of $\mathrm{P}-\mathrm{TEFb}$ required for productive elongation, significantly decreased accumulation of HIRA (Figure 5A), without affecting HIRA or PML protein levels (Figure 5B). In addition, DAXX presence in PML NBs was not affected by DRB (Sup. Figure 4A), underscoring the fact that PML NBs are still able to recruit client proteins under this treatment. Similar results were obtained with other CDK9 inhibitors such as LDC067 (simplified as CDK9i) or flavopiridol (Sup. Figure 4B).

To corroborate our findings, we used alternative transcriptional inhibitors such $\alpha$ amanitin, which triggers degradation of RNA polymerase II (59) or JQ1, a specific inhibitor for the bromodomains of the BET family proteins that inhibits Bromodomain protein 4 (BRD4) binding to acetylated histones and recruitment of p-TEFb (60). A significant decrease of HIRA localization in PML NBs in the presence of $\alpha$-amanitin was observed (Figure 5C), without impacting HIRA or PML protein levels (Figure 5D). Treatment of cells 
with JQ1 prior to IFN $\beta$ treatment also led to a significant decrease of HIRA accumulation in PML NBs (Sup. Figure 4C), while it did not impact DAXX presence in PML NBs (Sup. Figure 4A), nor impacted HIRA/PML levels (Sup. Figure 4D). Collectively, our results reveal that upon IFN $\beta$ treatment it is the transcriptional inhibition per se that prevents HIRA localization in PML NBs, despite a normal increase in PML valency. Those data, together with the regulation of the HIRA behavior in PML NBs according to the eH3.3 soluble pool, highly suggest that HIRA shuttles in PML NBs to retrieve H3.3-H4 dimers for deposition onto the chromatin following a burst of transcriptional activity.

\section{IFN-I stimulation triggers accumulation of endogenous $\mathrm{H} 3.3$ in the 3 ' end region of transcribed ISGs}

In order to further decipher the functional role of the PML NBs-HIRA-H3.3 axis, we decided to focus on the inflammatory transcriptional response, which has a crucial role in various physiological or pathological processes and during which HIRA is readily detectable in PML NBs. IFN-I is responsible for the upregulation of hundreds of genes, collectively known as ISGs that mainly interfere with virus replication (61). Using a tagged version of H3.3 in MEF cells, previous studies showed an increased and prolonged deposition of ectopic H3.3 in the transcription end sites (TES) region of ISGs upon IFN-I stimulation $(57,62)$. We thus wondered whether the PML NBs-HIRA-H3.3 axis could functionally impact H3.3 deposition patterns on ISGs.

To investigate this in an endogenous context, we took advantage of an H3.3-specific antibody, that was previously validated in ChIP (63), to monitor H3.3 occupancy on specific ISGs following IFN $\beta$-induced transcription. Levels of H3.3 were unaffected by 24 hours of IFN $\beta$ stimulation as seen by RT-QPCR or WB treatment (Sup. Figure 5A). We first investigated H3.3 incorporation on MX1,OAS1 and ISG54 (IFIT2) which are representative ISGs induced upon IFN $\beta$ stimulation. ChIP assays with the H3.3-specific antibody were performed over three distinct regions of the selected ISGs: the promoter region, located just upstream $(-120 \mathrm{pb})$ of the transcriptional start site (TSS), the middle of the coding region (mid), and a distal site in the coding region near the transcriptional end site (TES) (see map in Figure 6A). IFN $\beta$ treatment for 24 hours did not increase H3.3 occupancy at promoter regions, but rather slightly decreased it (Figure 6A). This reduction following IFN stimulation likely reflects transcription-induced nucleosome depletion known to happen for many genes (64). Remarkably, IFN $\beta$ stimulation induced H3.3 incorporation most noticeably over the distal sites of the coding regions (Figure 6A). Use of a nontargeting IgG antibody did not lead to any significant amount of immunoprecipitated DNA (\% input) in any of the conditions highlighting the specificity of our ChIP experiment (Sup. Figure 5B). In addition, no change in H3.3 occupancy was observed at an enhancer region known to be enriched with H3.3 (46), underscoring the specificity of H3.3 incorporation in ISGs (Figure 6A). Normalization of H3.3 signal over the total H3 histones signal, that showed no major changes in histone density, confirmed the increased amount of H3.3 at ISGs with a preference for the TES region, thus verifying the known replicationindependent replacement of canonical H3 histones with H3.3 during transcription (Sup. Figure 5C) (64-66). To investigate the relationship between IFN-induced H3.3 deposition and ISGs expression, we performed ChIP-QPCR in a time-course after IFN $\beta$ stimulation. When looking at H3.3 deposition, no significant increase was observed at representative mid or TES regions at 6 or 12 hours of IFN $\beta$ treatment (Sup. Figure 5D) suggesting that the induced H3.3-deposition is taking place after the peak of transcription at 6 hours (Sup. Figure 5E). Importantly, the induced H3.3 deposition seen at 24 hours of IFN $\beta$ continued 
for an extended period of time and was even higher after 48 hours of IFN $\beta$ suggesting that it may leave a long-lasting chromatin mark on ISGs (Sup. Figure 5D).

To get a more comprehensive picture of endogenous H3.3 deposition, we performed ChIPSeq analyses on cells treated with IFN $\beta$ for 24 hours. We first examined H3.3 enrichment over the gene bodies of a published panel of equivalent sized ISGs or non-interferon stimulated genes (non-ISGs) (38). The levels of H3.3 significantly increased on ISGs in IFN $\beta$-treated cells with a clear bias towards the TES region of the genes (Figure 6B). The drop of $\mathrm{H} 3.3$ at the TSS region was higher in IFN $\beta$-stimulated cells reflecting transcription-induced nucleosome depletion as observed by QPCR. In contrast, no significant difference of H3.3 enrichment could be observed across the non-ISGs (Figure 6C). We selected genes for which the difference in H3.3 enrichment at the TES region between IFN $\beta$ treated and non-treated cells was the highest and performed Gene Ontology (GO) analysis to get a view of their nature. GO analysis showed an enrichment in genes involved in IFN $\alpha$ and IFN $\gamma$ response comforting the specific enrichment of H3.3 on the TES region of ISGs as a prolonged response after IFN $\beta$ stimulus (Figure 6D). In addition, to evaluate the identity of H3.3-enriched genes in an unbiased manner, we performed an independent GO analysis on all genes found in our ChIP peak calls. This yielded similar results with IFN $\alpha$ and IFN $\gamma$ responses being the most highly significant GO terms (Sup. Figure 5F). Thus, these findings establish that IFN-I triggers a specific longlasting H3.3 deposition on genes linked to IFN response.

\section{H3.3 deposition on transcribed ISGs is impaired upon HIRA or PML depletion}

HIRA is involved in deposition of H3.3 in genic regions coupled to transcription $(19,21$ $23,46,57)$ as well as in H3.3 recycling (58). In addition, PML NBs have been proposed to facilitate the routing of $\mathrm{H} 3.3$ histones and their histone chaperones from the nucleoplasm to chromatin $(30,31)$. As shown above, following IFN $\beta$ stimulation, HIRA accumulates in PML NBs together with soluble H3.3 and H3.3 accumulate on the 3' end of ISGs. HIRA is not directly implicated in the transcriptional upregulation of ISGs (Sup. Figure 6A). We thus wondered whether HIRA was essential for H3.3 deposition at ISGs observed mainly in the TES region. We performed ChIP-QPCR analysis in cells depleted of HIRA or PML and treated with IFN $\beta$ for 24 hours. Knock-down efficiency was verified by western blot analysis and showed a strong depletion of both proteins (Figure 6E). When looking at mid or TES regions of selected ISGs, we observed a moderate but consistent decrease in H3.3 deposition in absence of HIRA or PML (Figure 6E), suggesting the importance of these two proteins for the long-lasting H3.3 deposition on ISGs. ChIP-Seq analysis of HIRA-depleted or PML-depleted cells showed a significant decrease ( $\mathrm{p}$-value $=4,76 \mathrm{e}-03$ or $1.262 \mathrm{e}-03$ respectively, as assessed by a paired Student's t-test) in the loading of H3.3 at the TES on the panel of ISGs (Figure 6F). Representative STAT1 and GCH1 genes, confirmed the deficit in H3.3 loading at the TES of ISGs in the absence of HIRA or PML (Figure 6G). We thus conclude that HIRA and PML both contribute to the increased long-lasting H3.3 deposition in the TES region of ISGs during the transcription process associated to IFN stimulus.

\section{Discussion}

There has been considerable efforts in defining the multiple roles of PML NBs in the recent years including in chromatin dynamics. Our work underscores the role of PML NBs for the HIRA-mediated H3.3-deposition on transcriptionally active ISGs, thus strongly supporting a role of PML NBs in H3.3 chromatin assembly pathways as well as in transcriptional 
regulation (3). We discuss how this PML NBs-HIRA chaperone axis may help to fine-tune H3.3 deposition during transcription which could impact epigenetic memory.

\section{HIRA accumulation in PML NBs upon inflammatory stresses}

While senescence was the first stress shown to induce accumulation of HIRA complex in PML NBs (33-36), IFN-I signaling pathway was recently shown to be responsible for the accumulation of HIRA after a viral infection (37-39). Here, we first extend and corroborate these findings by showing that various inflammatory stresses, including TNF $\alpha$, or a synthetic dsRNA (PolyI:C), which triggers IFN-I signaling pathway through Pattern Recognition Receptors (PRRs), can also mediate HIRA recruitment in PML NBs. Inflammatory responses play an essential role in a wide range of physiological and pathological biological phenomena such as viral infection, DNA damage, or aging (67). In particular, the recent SARS-CoV-2 pandemic, causing COVID-19, has underlined importance of the innate immune that triggers transcription of IFN-I, as well as of TNF $\alpha$, followed by induction of numerous ISGs with various anti-viral functions (for review (68)). Impaired IFN-I response was recently associated with COVID-19 severity (69, 70)(for review (68)). Interestingly, members of the HIRA chaperone complex as well as PML have been identified as anti-viral factors in a genome-wide CRISPR screen (71). Our study underscoring the importance of a PML NBs-HIRA axis to mediate H3.3 deposition on ISGs upon inflammatory responses thus raises the possibility that this mechanism could participate in HIRA and PML anti-viral roles in the context of COVID-19, although it remains to be investigated.

\section{HIRA recruitment in PML NBs is dependent on functional SUMO/SIM interactions}

One common characteristic of the various stresses allowing accumulation of HIRA in PML NBs in primary cells is the increase in PML valency which prompted us to investigate its functional importance. Indeed, regulation of the composition of PML NBs implies SUMO/SIM interaction modules whose valency and affinity regulate interactions between the PML scaffold protein and client proteins (3). Here, we show that HIRA partitioning in PML NBs upon IFN-I is, in part, mediated by SUMO/SIM interactions, that can be inhibited with specific Affimers. Interestingly, HIRA and/or UBN1 were identified as SUMOylated proteins on K809 and K530 respectively in various SUMO screens (72, 73). However, our western blot analysis as well as results from McFarlane et al. (38) do not support major stable modifications of HIRA with SUMO groups upon IFN $\beta$ stimulation. In addition, ectopic HIRA mutated on a K809 was still recruited in PML NBs similar to the wild-type protein (Sup. Figure 6B), suggesting that lysine K809 is dispensable for HIRA recruitment in PML NBs. Our data using Pml/- MEFs reconstituted with PML WT or PML 3K further confirm the importance of PML main SUMOylation sites in recruiting HIRA complex upon IFN-I.

Remarkably, SIM-containing clients, as exemplified with DAXX (8), are favored for partitioning in endogenous PML NBs containing a higher valency of SUMO sites compared to SIM sites (50). Here, we identified a putative SIM motif on HIRA sequence that may participate in HIRA complex recruitment in PML NBs. Interestingly, the VLRL SIM motif identified is followed by a Serine. Phosphorylation adjacent to SIM motifs could lead to an increased affinity towards SUMO1 lysine residues (74). One could hypothesize that other post-translational modifications such as phosphorylation could thus be important in regulating HIRA partitioning by changing the affinity between HIRA and SUMOylated PML proteins/partners. Of note, glycogen synthase kinase $3 \beta$ (GSK-3 $\beta$ ) mediatedphosphorylation of HIRA on S697 was suggested to drive HIRA accumulation in PML NBs 
upon senescence entry (75). However, we did not observe any defects in the localization of an ectopic form of HIRA mutated on S697 (HIRA-HA S697A) upon IFN $\beta$ stimulation (Sup. Figure 6C), and GSK-3 $\beta$ inhibitors did not alleviate the localization of HIRA in PML NBs in response to IFN $\beta$ stimulation (38). Thus, HIRA accumulation in PML NBs relies on SUMO/SIM interactions after IFN-I. Whether this is mediated by direct interactions with SUMOylated PML or indirect interactions via Sp100 (38) remains to be investigated. Nevertheless, the use of SUMO-specific Affimers opens up interesting avenues to interfere with client recruitments in PML NBs including HIRA, but caution should be taken with their use since they inhibit all SUMO/SIM interactions.

\section{HIRA accumulation in PML NBs depends on the availability of an H3.3-H4 pool and on transcriptional activity}

Importantly, although SUMO/SIM interactions might play an important role to mediate HIRA accumulation in PML NBs, our study unveils the availability of H3.3 within PML NBs as a novel important parameter controlling this accumulation. DAXX is essential for the correct folding of H3.3-H4 dimers (76) as well as other proteins as shown recently (77). Knockdown of DAXX leads to destabilization of both the DAXX chaperone and the H3.3$\mathrm{H} 4$ dimers, and it prevents localization of neosynthesized H3.3-H4 dimers in PML NBs in primary cells $(30,31,76)$. We now show that knockdown of DAXX results in HIRA accumulation in PML NBs, in a manner that is independent on the increase in PML valency. In addition, overexpression of a pool of soluble $\mathrm{H} 3.3-\mathrm{H} 4$ in the nucleoplasm prevents HIRA accumulation in PML NBs upon IFN-I treatment. Our results thus raise the possibility that HIRA travels through PML NBs as a normal process happening in untreated cells as a means to retrieve folded H3.3-H4 dimers present in PML NBs (Figure 7). Residence time of HIRA would not be sufficient to mediate its accumulation in PML NBs in a normal situation. However, under circumstances where there is a shortage of H3.3-H4 dimers as compared to the number of HIRA proteins in PML NBs, HIRA may then accumulate in the nuclear bodies as a result of an increased residence time. Of note, overexpression of an ectopic HIRA leads to its accumulation in PML NBs in untreated cells (Sup. Figure 6D) supporting the hypothesis that PML NBs are a normal thoroughfare for HIRA, that accumulates there when expressed at higher levels.

Recently, the use of an APEX2 peroxidase fused to PML in mouse ESCs to mediate chromatin labeling and purification combined with deep-sequencing (ALaP-Seq) allowed the identification of chromatin regions proximal to PML NBs. PML NBs were shown to associate with active genes located in an open chromatin environment, confirming previous studies on the localization of PML NBs in regions of high transcriptional activity with nascent transcripts found on the surface of PML NBs $(9,11,12)$. Remarkably, inhibition of transcription leads to a reduction of the physical contacts between chromatin and PML NBs (78). Using various transcriptional inhibitors, including CDK9 inhibitors, $\alpha$-amanitin or the BET inhibitor JQ1, we show that HIRA recruitment in PML NBs is dependent on transcription per se (Figure 5), implying that transcriptional activity drives HIRA through PML NBs. Upon IFN-I treatment, H3.3 mRNA and protein levels remain constant (Sup. Figure 5A), yet, the high transcriptional activity of thousands of genes demands high amounts of H3.3-H4 to be deposited in a replication-independent manner. HIRA would thus accumulate in PML NBs in a situation of high transcriptional activity before mediating transcription-coupled H3.3 deposition on active genes located in the vicinity of PML NBs.

Importantly, our model defining the availability of H3.3-H4 dimers in PML NBs as a crucial parameter governing accumulation of HIRA in PML NBs provides a novel explanation for 
the absence of HIRA in PML NBs in cancer cells, which has remained enigmatic for years. Indeed, even though cancer cells express similar HIRA levels and respond to IFN $\beta$ by increasing PML protein and SUMOylation levels (Sup. Figure 3A-B), they do not present HIRA accumulation in PML NBs upon various stresses (Sup. Figure 3A-B) $(38,39)$. In addition, while carcinoma cells are frequently mutated in pRB or p53 tumor suppressor pathways, accumulation of HIRA to PML NBs in senescent cells does not require these functional pathways (79) suggesting the existence of an, as yet undefined, process controlling its accumulation in a cell-type specific manner. Here, we suggest that presence of neosynthesized H3.3-H4 dimers in PML NBs, which is impaired in cancer cells (Sup. Figure 3E), is key to explain accumulation of HIRA in PML NBs. Further studies should thus aim at understanding why PML NBs does not seem to act as meeting places for H3.3 and their chaperones in cancer cells.

\section{H3.3-induced deposition in the TES region of transcribed ISGs is mediated by HIRA and PML}

Given the relationship between PML NBs, HIRA and H3.3 upon IFN-I treatment, we investigated the role of HIRA in the H3.3-mediated deposition on ISGs. We first show that endogenous H3.3 displays a long-lasting deposition, increasing after the peak of transcription of the ISGs up to $48 \mathrm{~h}$ after IFN-I stimulation, and with a strong preference for the TES region, consistent with previous reports obtained in MEF cells $(57,62)$. Deposition of endogenous H3.3 was reduced in the absence of PML consistent with the role of PML NBs in targeting H3.3 to chromatin (30) and in line with the role of PML in chromatinization of latent viral genomes (37). Alternatively, while PML depletion impairs transcription of ISGs (Sup. Figure 6A) and (80), it could indirectly affect H3.3 deposition at TES regions, which is linked to transcriptional activity per se of ISGs (57). In addition, PML could directly be implicated in loading of HIRA on ISGs (38), thus affecting H3.3 deposition. HIRA depletion also impaired H3.3 deposition consistent with its known function in H3.3-nucleosome assembly. HIRA interacts with RNA pol II and also with H3K36me3 $(21,58)$, a histone mark added by the methyltransferase SETD2, which moves with RNA pol II during transcription. In MEFs, HIRA also interacts with WHSC1, an H3K36me3 methyltransferase that recruits HIRA for prolonged H3.3 deposition on ISGs (57). Since H3K36me3 was also found to be enriched in the TES part of ISGs in IFN $\beta$ treated cells (Sup. Figure 6E), one could thus hypothesize that similar recruitment of HIRA via the H3K36methyltransferase/H3K36me3 mark might be at play.

The role of the prolonged H3.3 deposition on ISGs can be multiple. First, this long-lasting mark could contribute to the acquisition of a functional IFN response memory. Indeed, H3.3 was shown to mediate memory of an active state upon nuclear transfer in Xenopus laevis (81). In addition, in mouse embryonic fibroblasts, IFN $\beta$ stimulation creates a transcriptional memory of a subset of ISGs, which coincides with acquisition of H3.3 and H3K36me3 on chromatin (82). Second stimulation with IFN $\beta$ allows a faster and greater transcription of memory ISGs, which is dependent on H3.3 deposition in the first stimulation phase (82). However, H3.3 mark could only mediate a short-term memory as shown recently in IFN $\gamma$ memory in HeLa cells (83). In HeLa cells, PML was required for the stronger re-expression of HLA-DRA after IFN $\gamma$ restimulation, a locus that remained juxtaposed to PML NBs after transcription shut-off (84). Alternatively, H3.3 deposition may also serve to directly regulate ISGs expression. In mouse cells, H3.3 was found to be phosphorylated on Serine 31 on stimulation-induced genes, a mark that could serve as an ejection switch of the ZMYND11 transcriptional repressor thus amplifying the 
transcription of these genes (85). Whether H3.3S31P is increased on ISGs upon IFN-I remains to be investigated.

In conclusion, we propose the following model for the role of a PML NBs-HIRA-H3.3 axis during inflammatory response (Figure 7). HIRA drives through PML NBs in an transcriptional dependent manner to get H3.3-H4 dimers before deposition onto active genes. IFN-I treatment triggers accumulation of HIRA into PML NBs followed by prolonged HIRA-mediated H3.3 deposition on ISGs, which could potentially serve to mediate a short-term epigenetic memory of the transcriptional status. Thus, our findings highlight the importance of the interplay between PML NBs and H3.3 chromatin dynamics to maintain gene expression patterns and chromatin homeostasis.

\section{Data Availability}

The ChIP-Seq datasets have been deposited in the Gene Expression Omnibus (GEO; http://www.ncbi.nlm.nig.gov/geo/) under the accession number GSE186937.

\section{Funding}

P.L. laboratory is funded by grants from the Centre National de la Recherche Scientifique (CNRS), Institut National de la Santé et de la Recherche Médicale (INSERM), University Claude Bernard Lyon 1, French National Agency for Research-ANR [EPIPRO ANR-18CE15-0014-01, CHROMACoV ANR-20-COV9-0004]; LabEX DEVweCAN and DEV2CAN [ANR-10-LABX-61]; AFM MyoNeurALP, the Comité départemental du Rhône de La Ligue contre le Cancer and the Fondation pour la Recherche Médicale (FRM). P.L. is a CNRS Research Director and AC is assistant professor in the University Claude Bernard Lyon 1. Conflict of interest statement. None declared.

\section{Acknowledgments}

We thank Dr. Valérie Lallemand-Breitenbach for the Pml WT and Pml-/- MEFs. We thank Dr. Chris Boutell for the pLVX-His-SUM01/2/3 plasmids. We thank Dr. Roger Everett for the PML-containing plasmids. We thank Dr. David J. Hughes for the SUMO-specific Affimers plasmids. We thank Lars Jansen for the pBABE-H3.3-SNAP-HA3 plasmid.

\section{References}

1. Banani,S.F., Lee,H.O., Hyman,A.A. and Rosen,M.K. (2017) Biomolecular condensates: organizers of cellular biochemistry. Nature Reviews Molecular Cell Biology, 18, 285-298.

2. Lallemand-Breitenbach,V. and de Thé,H. (2018) ScienceDirectPML nuclear bodies: from architecture to function. Current Opinion in Cell Biology, 52, 154-161.

3. Corpet,A., Kleijwegt,C., Roubille,S., Juillard,F., Jacquet,K., Texier,P. and Lomonte,P. (2020) PML nuclear bodies and chromatin dynamics: catch me if you can! Nucleic Acids Research, 389, 251-23.

4. Li,Y., Ma,X., Wu,W., Chen,Z. and Meng,G. (2020) PML Nuclear Body Biogenesis, Carcinogenesis, and Targeted Therapy. Trends Cancer, 10.1016/j.trecan.2020.05.005.

5. Van Damme,E., Laukens,K., Dang,T.H. and Van Ostade,X. (2010) A manually curated network of the PML nuclear body interactome reveals an important role for PML-NBs in SUMOylation dynamics. Int. J. Biol. Sci., 6, 51-67.

6. de Thé,H., Le Bras,M. and Lallemand-Breitenbach,V. (2012) The cell biology of disease: Acute promyelocytic leukemia, arsenic, and PML bodies. Journal of Cell Biology, 198, 11-21. three major sentrinization sites in PML. J Biol Chem, 273, 26675-26682. 
8. Sahin,U., Ferhi,O., Jeanne,M., Benhenda,S., Berthier,C., Jollivet,F., Niwa-Kawakita,M., Faklaris,O., Setterblad,N., de The,H., et al. (2014) Oxidative stress-induced assembly of PML nuclear bodies controls sumoylation of partner proteins. J Cell Biol, 204, 931-945.

9. Boisvert,F.-M., Hendzel,M.J. and Bazett-Jones,D.P. (2000) Promyelocytic leukemia (PML) nuclear bodies are protein structures that do not accumulate RNA.J Cell Biol, 148, 283-292.

10. Shiels,C., Islam,S.A., Vatcheva,R., Sasieni,P., Sternberg,M.J., Freemont,P.S. and Sheer,D. (2001) PML bodies associate specifically with the MHC gene cluster in interphase nuclei. Journal of Cell Science, 114, 3705-3716.

11. Wang,J. (2004) Promyelocytic leukemia nuclear bodies associate with transcriptionally active genomic regions. J Cell Biol, 164, 515-526.

12. Kurihara,M., Kato,K., Sanbo,C., Shigenobu,S., Ohkawa,Y., Fuchigami,T. and Miyanari,Y. (2020) Genomic Profiling by ALaP-Seq Reveals Transcriptional Regulation by PML Bodies through DNMT3A Exclusion. Molecular Cell, 78, 493-505.e8.

13. Ching,R.W., Ahmed,K., Boutros,P.C., Penn,L.Z. and Bazett-Jones,D.P. (2013) Identifying gene locus associations with promyelocytic leukemia nuclear bodies using immuno-TRAP. J Cell Biol, 201, 325335.

14. Kumar,P.P., Bischof,O., Purbey,P.K., Notani,D., Urlaub,H., Dejean,A. and Galande,S. (2007) Functional interaction between PML and SATB1 regulates chromatin-loop architecture and transcription of the MHC class I locus. Nat Cell Biol, 9, 45-56.

15. Chang,F.T.M., McGhie,J.D., Chan,F.L., Tang,M.C., Anderson,M.A., Mann,J.R., Andy Choo,K.H. and Wong,L.H. (2013) PML bodies provide an important platform for the maintenance of telomeric chromatin integrity in embryonic stem cells. Nucleic Acids Research, 41, 4447-4458.

16. Delbarre,E., Ivanauskiene,K., Spirkoski,J., Shah,A., Vekterud,K., Moskaug,J.Ø., Bøe,S.O., Wong,L.H., Küntziger,T. and Collas,P. (2017) PML protein organizes heterochromatin domains where it regulates histone H3.3 deposition by ATRX/DAXX. Genome Research, 27, 913-921.

17. Delbarre,E. (2021) Modulation of H3.3 chromatin assembly by PML: a way to regulate epigenetic inheritance. Bioessays.

18. Allis,C.D. and Jenuwein,T. (2016) The molecular hallmarks of epigenetic control. Nature Reviews Genetics, 17, 487-500.

19. Martire,S. and Banaszynski,L.A. (2020) The roles of histone variants in fine-tuning chromatin organization and function. Nature Reviews Molecular Cell Biology, 10.1038/s41580-020-0262-8.

20. Ray-Gallet,D., Quivy,J.-P., Scamps,C., Martini,E.M.-D., Lipinski,M. and Almouzni,G. (2002) HIRA is critical for a nucleosome assembly pathway independent of DNA synthesis. Molecular Cell, 9, 1091-1100.

21. Ray-Gallet,D., Woolfe,A., Vassias,I., Pellentz,C., Lacoste,N., Puri,A., Schultz,D.C., Pchelintsev,N.A., Adams,P.D., Jansen,L.E.T., et al. (2011) Dynamics of Histone H3 Deposition In Vivo Reveal a Nucleosome Gap-Filling Mechanism for H3.3 to Maintain Chromatin Integrity. Molecular Cell, 44, 928-941.

22. Goldberg,A.D., Banaszynski,L.A., Noh,K.-M., Lewis,P.W., Elsaesser,S.J., Stadler,S., Dewell,S., Law,M., Guo,X., Li,X., et al. (2010) Distinct factors control histone variant H3.3 localization at specific genomic regions. Cell, 140, 678-691.

23. Zhang,H., Gan,H., Wang,Z., Lee,J.-H., Zhou,H., Ordog,T., Wold,M.S., Ljungman,M. and Zhang,Z. (2017) RPA Interacts with HIRA and Regulates H3.3 Deposition at Gene Regulatory Elements in Mammalian Cells. Molecular Cell, 65, 272-284. 
bioRxiv preprint doi: https://doi.org/10.1101/2021.11.30.470516; this version posted December 1,2021 . The copyright holder for this

preprint (which was not certified by peer review) is the author/funder. All rights reserved. No reuse allowed without permission.

24. Ricketts,M.D. and Marmorstein,R. (2016) A Molecular Prospective for HIRA Complex Assembly and H3.3-Specific Histone Chaperone Function. J. Mol. Biol., 10.1016/j.jmb.2016.11.010.

25. Tang,Y., Poustovoitov,M.V., Zhao,K., Garfinkel,M., Canutescu,A., Dunbrack,R., Adams,P.D. and Marmorstein,R. (2006) Structure of a human ASF1a-HIRA complex and insights into specificity of histone chaperone complex assembly. Nat Struct Mol Biol, 13, 921-929.

26. Drane,P., Ouararhni,K., Depaux,A., Shuaib,M. and Hamiche,A. (2010) The death-associated protein DAXX is a novel histone chaperone involved in the replication-independent deposition of H3.3. Genes \& Development, 24, 1253-1265.

27. Voon,H.P.J., Hughes,J.R., Rode,C., La Rosa-Velázquez,De,I.A., Jenuwein,T., Feil,R., Higgs,D.R. and Gibbons,R.J. (2015) ATRX Plays a Key Role in Maintaining Silencing at Interstitial Heterochromatic Loci and Imprinted Genes. CellReports, 10.1016/j.celrep.2015.03.036.

28. Elsässer,S.J., Noh,K.-M., Diaz,N., Allis,C.D. and Banaszynski,L.A. (2015) Histone H3.3 is required for endogenous retroviral element silencing in embryonic stem cells. Nature, 10.1038/nature14345.

29. Sadic,D., Schmidt,K., Groh,S., Kondofersky,I., Ellwart,J., Fuchs,C., Theis,F.J. and Schotta,G. (2015) Atrx promotes heterochromatin formation at retrotransposons. EMBO Rep, 16, 836-850.

30. Delbarre,E., Ivanauskiene,K., Küntziger,T. and Collas,P. (2013) DAXX-dependent supply of soluble (H3.3-H4) dimers to PML bodies pending deposition into chromatin. Genome Research, 23, 440-451.

31. Corpet,A., Olbrich,T., Gwerder,M., Fink,D. and Stucki,M. (2014) Dynamics of histone H3.3 deposition in proliferating and senescent cells reveals a DAXX-dependent targeting to PML-NBs important for pericentromeric heterochromatin organization. Cell Cycle, 113, E3213-E3220.

32. Ivanauskiene,K., Delbarre,E., McGhie,J.D., Kuntziger,T., Wong,L.H. and Collas,P. (2014) The PMLassociated protein DEK regulates the balance of H3.3 loading on chromatin and is important for telomere integrity. Genome Research, 10.1101/gr.173831.114.

33. Rai,T.S., Puri,A., McBryan,T., Hoffman,J., Tang,Y., Pchelintsev,N.A., van Tuyn,J., Marmorstein,R., Schultz,D.C. and Adams,P.D. (2011) Human CABIN1 Is a Functional Member of the Human HIRA/UBN1/ASF1a Histone H3.3 Chaperone Complex. Molecular and Cellular Biology, 31, 41074118.

34. Zhang,R., Poustovoitov,M.V., Ye,X., Santos,H.A., Chen,W., Daganzo,S.M., Erzberger,J.P., Serebriiskii,I.G., Canutescu,A.A., Dunbrack,R.L., et al. (2005) Formation of MacroH2A-containing senescenceassociated heterochromatin foci and senescence driven by ASF1a and HIRA. Developmental Cell, 8, 19-30.

35. Banumathy,G., Somaiah,N., Zhang,R., Tang,Y., Hoffmann,J., Andrake,M., Ceulemans,H., Schultz,D., Marmorstein,R. and Adams,P.D. (2009) Human UBN1 Is an Ortholog of Yeast Hpc2p and Has an Essential Role in the HIRA/ASF1a Chromatin-Remodeling Pathway in Senescent Cells. Molecular and Cellular Biology, 29, 758-770.

36. Jiang,W.-Q., Nguyen,A., Cao,Y., Chang,A.C.-M. and Reddel,R.R. (2011) HP1-Mediated Formation of Alternative Lengthening of Telomeres-Associated PML Bodies Requires HIRA but Not ASF1a. PLoS ONE, 6, e17036.

37. Cohen,C., Corpet,A., Roubille,S., Maroui,M.A., Poccardi,N., Rousseau,A., Kleijwegt,C., Binda,O., Texier,P., Sawtell,N., et al. (2018) Promyelocytic leukemia (PML) nuclear bodies (NBs) induce latent/quiescent HSV-1 genomes chromatinization through a PML NB/Histone H3.3/H3.3 Chaperone Axis. PLoS Pathogens, 14, e1007313.

38. McFarlane,S., Orr,A., Roberts,A.P.E., Conn,K.L., Iliev,V., Loney,C., da Silva Filipe,A., Smollett,K., Gu,Q., Robertson,N., et al. (2019) The histone chaperone HIRA promotes the induction of host innate immune defences in response to HSV-1 infection. PLoS Pathogens, 15, e1007667. 
39. Rai,T.S., Glass,M., Cole,J.J., Rather,M.I., Marsden,M., Neilson,M., Brock,C., Humphreys,I.R., Everett,R.D. and Adams,P.D. (2017) Histone chaperone HIRA deposits histone H3.3 onto foreign viral DNA and contributes to anti-viral intrinsic immunity. Nucleic Acids Research, 45, 11673-11683.

40. Hughes,D.J., Tiede,C., Penswick,N., Tang,A.A.-S., Trinh,C.H., Mandal,U., Zajac,K.Z., Gaule,T., Howell,G., Edwards,T.A., et al. (2017) Generation of specific inhibitors of SUMO-1- and SUMO-2/3-mediated protein-protein interactions using Affimer (Adhiron) technology. Sci Signal, 10.

41. Adam,S., Polo,S.E. and Almouzni,G. (2013) Transcription Recovery after DNA Damage Requires Chromatin Priming by the H3.3 Histone Chaperone HIRA. Cell, 155, 94-106.

42. Everett,R.D., Rechter,S., Papior,P., Tavalai,N., Stamminger,T. and Orr,A. (2006) PML Contributes to a Cellular Mechanism of Repression of Herpes Simplex Virus Type 1 Infection That Is Inactivated by ICP0. Journal of Virology, 80, 7995-8005.

43. Lallemand-Breitenbach,V., Jeanne,M., Benhenda,S., Nasr,R., Lei,M., Peres,L., Zhou,J., Zhu,J., Raught,B. and de Thé,H. (2008) Arsenic degrades PML or PML-RAR $\alpha$ through a SUMO-triggered RNF4/ubiquitin-mediated pathway. Nat Cell Biol, 10, 547-555.

44. Yao,Q., Li,H., Liu,B.-Q., Huang,X.-Y. and Guo,L. (2011) SUMOylation-regulated protein phosphorylation, evidence from quantitative phosphoproteomics analyses. Journal of Biological Chemistry, 286, 27342-27349.

45. Rojas-Fernandez,A., Plechanovova,A., Hattersley,N., Jaffray,E., Tatham,M.H. and Hay,R.T. (2014) SUMO Chain-Induced Dimerization Activates RNF4. Molecular Cell, 53, 880-892.

46. Pchelintsev,N.A., McBryan,T., Rai,T.S., van Tuyn,J., Ray-Gallet,D., Almouzni,G. and Adams,P.D. (2013) Placing the HIRA Histone Chaperone Complex in the Chromatin Landscape. CellReports, 3, 10121019.

47. Cheon,H., Holvey-Bates,E.G., Schoggins,J.W., Forster,S., Hertzog,P., Imanaka,N., Rice,C.M., Jackson,M.W., Junk,D.J. and Stark,G.R. (2013) IFN-dependent increases in STAT1, STAT2, and IRF9 mediate resistance to viruses and DNA damage. The EMBO Journal, 32, 2751-2763.

48. Zhang,Y., Liu,T., Meyer,C.A., Eeckhoute,J., Johnson,D.S., Bernstein,B.E., Nusbaum,C., Myers,R.M., Brown,M., Li,W., et al. (2008) Model-based analysis of ChIP-Seq (MACS). Genome Biol, 9, R137-9.

49. Kuleshov,M.V., Jones,M.R., Rouillard,A.D., Fernandez,N.F., Duan,Q., Wang,Z., Koplev,S., Jenkins,S.L., Jagodnik,K.M., Lachmann,A., et al. (2016) Enrichr: a comprehensive gene set enrichment analysis web server 2016 update. Nucleic Acids Research, 44, W90-7.

50. Banani,S.F., Rice,A.M., Peeples,W.B., Lin,Y., Jain,S., Parker,R. and Rosen,M.K. (2016) Compositional Control of Phase-Separated Cellular Bodies. Cell, 166, 651-663.

51. Lavau,C., Marchio,A., Fagioli,M., Jansen,J., Falini,B., Lebon,P., Grosveld,F., Pandolfi,P.P., Pelicci,P.G. and Dejean,A. (1995) The acute promyelocytic leukaemia-associated PML gene is induced by interferon. Oncogene, 11, 871-876.

52. Gao,C., Cheng,X., Lam,M., Liu,Y., Liu,Q., Chang,K.-S. and Kao,H.-Y. (2008) Signal-dependent Regulation of Transcription by Histone Deacetylase 7 Involves Recruitment to Promyelocytic Leukemia Protein Nuclear Bodies. Molecular Biology of the Cell, 19, 3020-3027.

53. Sahin,U., Jollivet,F., Berthier,C., de Thé,H. and Lallemand-Breitenbach,V. (2016) Detection of Protein SUMOylation In Situ by Proximity Ligation Assays. Methods Mol. Biol., 1475, 139-150.

54. Stadler,M., Chelbi-Alix,M.K., Koken,M.H., Venturini,L., Lee,C., Saïb,A., Quignon,F., Pelicano,L., Guillemin,M.C. and Schindler,C. (1995) Transcriptional induction of the PML growth suppressor gene by interferons is mediated through an ISRE and a GAS element. Oncogene, 11, 2565-2573. 
bioRxiv preprint doi: https://doi.org/10.1101/2021.11.30.470516; this version posted December $1,2021$. The copyright holder for this preprint (which was not certified by peer review) is the author/funder. All rights reserved. No reuse allowed without permission.

55. Beauclair,G., Bridier-Nahmias,A., Zagury,J.-F., Saïb,A. and Zamborlini,A. (2015) JASSA: a comprehensive tool for prediction of SUMOylation sites and SIMs. Bioinformatics, 31, 3483-3491.

56. Zhao,Q., Xie,Y., Zheng,Y., Jiang,S., Liu,W., Mu,W., Liu,Z., Zhao,Y., Xue,Y. and Ren,J. (2014) GPS-SUMO: a tool for the prediction of sumoylation sites and SUMO-interaction motifs. Nucleic Acids Research, 42, W325-30.

57. Sarai,N., Nimura,K., Tamura,T., Kanno,T., Patel,M.C., Heightman,T.D., Ura,K. and Ozato,K. (2013) WHSC1 links transcription elongation to HIRA-mediated histone H3.3 deposition. The EMBO Journal, 32, 2392-2406.

58. Torné,J., Ray-Gallet,D., Boyarchuk,E., Garnier,M., Le Baccon,P., Coulon,A., Orsi,G.A. and Almouzni,G. (2020) Two HIRA-dependent pathways mediate H3.3 de novo deposition and recycling during transcription. Nat Struct Mol Biol, 389, 251-12.

59. Bensaude,0. (2014) Inhibiting eukaryotic transcription. Which compound to choose? How to evaluate its activity? Transcription, 2, 103-108.

60. Qi,J. (2014) Bromodomain and Extraterminal Domain Inhibitors (BETi) for Cancer Therapy: Chemical Modulation of Chromatin Structure. Cold Spring Harbor Perspectives in Biology, 6, a018663-a018663.

61. Schoggins,J.W. and Rice,C.M. (2011) Interferon-stimulated genes and their antiviral effector functions. Current Opinion in Virology, 1, 519-525.

62. Tamura,T., Smith,M., Kanno,T., Dasenbrock,H., Nishiyama,A. and Ozato,K. (2009) Inducible deposition of the histone variant H3.3 in interferon-stimulated genes. J Biol Chem, 284, 12217-12225.

63. Lee,J.-S., Mo,Y., Gan,H., Burgess,R.J., Baker,D.J., van Deursen,J.M. and Zhang,Z. (2019) Pak2 kinase promotes cellular senescence and organismal aging. Proceedings of the National Academy of Sciences, 1, 201903847.

64. Workman,J.L. (2006) Nucleosome displacement in transcription. Genes \& Development, 20, 20092017.

65. Ahmad,K. and Henikoff,S. (2002) The histone variant H3.3 marks active chromatin by replicationindependent nucleosome assembly. Molecular Cell, 9, 1191-1200.

66. Mito,Y., Henikoff,J.G. and Henikoff,S. (2005) Genome-scale profiling of histone H3.3 replacement patterns. Nat Genet, 37, 1090-1097.

67. Medzhitov,R. (2008) Origin and physiological roles of inflammation. Nature, 454, 428-435.

68. Schultze,J.L. and Aschenbrenner,A.C. (2021) COVID-19 and the human innate immune system. Cell, 184, 1671-1692.

69. Hadjadj,J., Yatim,N., Barnabei,L., Corneau,A., Boussier,J., Smith,N., Péré,H., Charbit,B., Bondet,V., Chenevier-Gobeaux,C., et al. (2020) Impaired type I interferon activity and inflammatory responses in severe COVID-19 patients. Science, 31, eabc6027-15.

70. Trouillet-Assant,S., Viel,S., Gaymard,A., Pons,S., Richard,J.-C., Perret,M., Villard,M., Brengel-Pesce,K., Lina,B., Mezidi,M., et al. (2020) Type I IFN immunoprofiling in COVID-19 patients. J. Allergy Clin. Immunol., 146, 206-208.e2.

71. Wei,J., Alfajaro,M.M., DeWeirdt,P.C., Hanna,R.E., Lu-Culligan,W.J., Cai,W.L., Strine,M.S., Zhang,S.-M., Graziano,V.R., Schmitz,C.O., et al. (2021) Genome-wide CRISPR Screens Reveal Host Factors Critical for SARS-CoV-2 Infection. Cell, 184, 76-91.e13.

72. Schimmel,J., Eifler,K., Sigurðsson,J.O., Cuijpers,S.A.G., Hendriks,I.A., Vries,M.V.-D., Kelstrup,C.D., Francavilla,C., Medema,R.H., Olsen,J.V., et al. (2014) Uncovering SUMOylation Dynamicsduring Cell- 
Cycle Progression Reveals FoxM1 as a Key Mitotic SUMO Target Protein. Molecular Cell, 53, 10531066.

73. Hendriks,I.A., D'Souza,R.C.J., Yang,B., Vries,M.V.-D., Mann,M. and Vertegaal,A.C.O. (2014) Uncovering global SUMOylation signaling networks in a site-specific manner. Nat Struct Mol Biol, 21, 927-936.

74. Cappadocia,L., Mascle,X.H., Bourdeau,V., Tremblay-Belzile,S., Chaker-Margot,M., Lussier-Price,M., Wada,J., Sakaguchi,K., Aubry,M., Ferbeyre,G., et al. (2015) Structural and Functional Characterizationof the Phosphorylation-Dependent Interaction between PML and SUM01. Structure/Folding and Design, 23, 126-138.

75. Ye,X., Zerlanko,B., Kennedy,A., Banumathy,G., Zhang,R. and Adams,P.D. (2007) Downregulation of Wnt Signaling Is a Trigger for Formation of Facultative Heterochromatin and Onset of Cell Senescence in Primary Human Cells. Molecular Cell, 27, 183-196.

76. DeNizio,J.E., Elsasser,S.J. and Black,B.E. (2014) DAXX co-folds with H3.3/H4 using high local stability conferred by the H3.3 variant recognition residues. Nucleic Acids Research, 10.1093/nar/gku090.

77. Huang,L., Agrawal,T., Zhu,G., Yu,S., Tao,L., Lin,J., Marmorstein,R., Shorter,J. and Yang,X. (2021) DAXX represents a new type of protein-folding enabler. Nature, 10.1038/s41586-021-03824-5.

78. Eskiw,C.H., Dellaire,G. and Bazett-Jones,D.P. (2004) Chromatin Contributes to Structural Integrity of Promyelocytic Leukemia Bodies through a SUMO-1-independent Mechanism. Journal of Biological Chemistry, 279, 9577-9585.

79. Ye,X., Zerlanko,B., Zhang,R., Somaiah,N., Lipinski,M., Salomoni,P. and Adams,P.D. (2007) Definition of pRB- and p53-Dependent and -Independent Steps in HIRA/ASF1a-Mediated Formation of Senescence-Associated Heterochromatin Foci. Molecular and Cellular Biology, 27, 2452-2465.

80. Alandijany,T., Roberts,A.P.E., Conn,K.L., Loney,C., McFarlane,S., Orr,A. and Boutell,C. (2018) Distinct temporal roles for the promyelocytic leukaemia (PML) protein in the sequential regulation of intracellular host immunity to HSV-1 infection. PLoS Pathogens, 14, e1006769.

81. Ng,R.K. and Gurdon,J.B. (2007) Epigenetic memory of an active gene state depends on histone H3.3 incorporation into chromatin in the absence of transcription. Nat Cell Biol, 10, 102-109.

82. Kamada,R., Yang,W., Zhang,Y., Patel,M.C., Yang,Y., Ouda,R., Dey,A., Wakabayashi,Y., Sakaguchi,K., Fujita,T., et al. (2018) Interferon stimulation creates chromatin marks and establishes transcriptional memory. Proceedings of the National Academy of Sciences, 115, E9162-E9171.

83. Siwek,W., Tehrani,S.S.H., Mata,J.F. and Jansen,L.E.T. (2020) Activation of Clustered IFNgamma Target Genes Drives Cohesin-Controlled Transcriptional Memory. Molecular Cell, 80, 396-409.e6.

84. Gialitakis,M., Arampatzi,P., Makatounakis,T. and Papamatheakis,J. (2010) Gamma InterferonDependent Transcriptional Memory via Relocalization of a Gene Locus to PML Nuclear Bodies. Molecular and Cellular Biology, 30, 2046-2056.

85. Armache,A., Yang,S., de Paz,A.M.X.N., Robbins,L.E., Durmaz,C., Cheong,J.Q., Ravishankar,A., Daman,A.W., Ahimovic,D.J., Klevorn,T.X.S., et al. (2020) Histone H3.3 phosphorylation amplifies stimulationinduced transcription. Nature, 10.1038/s41586-020-2533-0.

\section{Figure Legends \\ Figure 1. HIRA accumulation in PML NBs correlates with increased PML valency in primary cells.}

A-B. Fluorescence microscopy visualization of HIRA (green) and PML (red) in BJ cells treated with Poly(I:C) at $10 \mu \mathrm{g} / \mathrm{mL}$ for $24 \mathrm{~h}$ or with TNF $\alpha$ at $100 \mathrm{ng} / \mathrm{mL}$ for $24 \mathrm{~h}$. Ruxolitinib (Ruxo) was added at $2 \mu \mathrm{M}$ one hour before Poly(I:C) or TNF $\alpha$ treatment and for $25 \mathrm{~h}$. Cell 
nuclei are visualized by DAPI staining (grey). Scale bars represent $10 \mu \mathrm{m}$. Histograms (below) show quantitative analysis of cells with HIRA localization at PML NBs. p-values (Student t-test): ${ }^{*}<0,05 ;{ }^{* * * *}<0,0001$; ns: non significant. Numbers on all histograms represent the mean of 3 independent experiments ( \pm SD). C. (left) Western blot visualization of PML from total cell extracts of BJ cells treated with IFN $\beta$ at $1000 \mathrm{U} / \mathrm{mL}$ or Poly(I:C) for $24 \mathrm{~h}$ and with ruxolitinib (Ruxo) at $2 \mu \mathrm{M}$ one hour before treatment and for 25h. (right) Western blot visualization of PML from RIPA extracts of BJ cells treated with TNF $\alpha$ at $100 \mathrm{ng} / \mathrm{mL}$ for $24 \mathrm{~h}$ and with ruxolitinib (Ruxo) at $2 \mu \mathrm{M}$ one hour before treatment and for $25 \mathrm{~h}$. Tubulin is a loading control.

\section{Figure 2. HIRA recruitment to PML NBs is dependent on SUMO proteins.}

A. Fluorescence microscopy visualization of Proximity Ligation Assays (PLA) signals (red) obtained after incubation of anti-PML+anti-SUMO, anti-HIRA+anti-PML or antiHIRA+anti-SUMO antibodies on BJ cells treated or not with IFN $\beta$ at $1000 \mathrm{U} / \mathrm{mL}$ for $24 \mathrm{~h}$. Cell nuclei are visualized by DAPI staining (grey or blue on the merge). Scale bar represents $10 \mu \mathrm{m}$. B. Box-and-whisker plot shows the number of PLA spots detected in cells described in A. In average, 200 nuclei/condition were analyzed from 3 independent experiments. The line inside the box represents the median of all observations. p-values (Mann-Whitney u-test): ${ }^{* * * *}<0,0001$. C. Western-blot visualization of SUMO-1 and SUMO$2 / 3$ from total cellular extracts of BJ cells treated with $60 \mathrm{nM}$ of siRNAs against luciferase or SUMO-1+SUM0-2/3 for $48 \mathrm{~h}$ and with IFN $\beta$ at $1000 \mathrm{U} / \mathrm{mL}$ during the last $24 \mathrm{~h}$. Actin is a loading control. D. (left) Fluorescence microscopy visualization of HIRA (green) and PML (red) in BJ cells treated with siRNAs as described in C and with IFN $\beta$ at $1000 \mathrm{U} / \mathrm{mL}$ or with etoposide (Etop) at $10 \mu \mathrm{M}$ for the last $24 \mathrm{~h}$ of siRNAs treatment. (right) Histograms show quantitative analysis of cells with HIRA localization at PML NBs. Numbers represent the mean of 3 independent experiments $( \pm S D)$. p-values (Student t-test): ${ }^{*}<0,05$.

\section{Figure 3. HIRA recruitment to PML NBs relies on SIM-SUMO interactions.}

A. Experimental design to assess SUMO-specific Affimers impact on HIRA relocalization to PML NBs. BJ cells were transduced with a Dox-inducible lentiviral vector encoding for

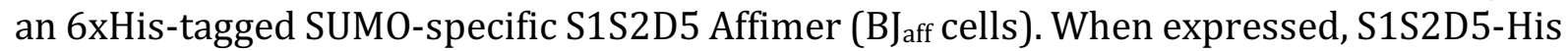
Affimers localize at PML NBs through their interactions with SUMOylated PML. B. Fluorescence microscopy visualization PML (cyan) and S1S2D5-His Affimer (red) in BJ aff cells induced or not with doxycycline at $100 \mathrm{nM}$ for $30 \mathrm{~h}$. Colocalization of the S1S2D5-His Affimer (red) and PML NBs (cyan) produces white spots. C. Fluorescence microscopy visualization HIRA (green) and S1S2D5-His Affimer (red) in BJ aff cells induced or not with doxycycline at $100 \mathrm{nM}$ for $30 \mathrm{~h}$ and treated with IFN $\beta$ at $1000 \mathrm{U} / \mathrm{mL}$ for the last $24 \mathrm{~h}$. Cell nuclei are visualized by DAPI staining (grey). Scale bars represent $10 \mu \mathrm{m}$. Histogram (right) shows quantitative analysis of cells with HIRA localization at PML NBs. Numbers represent the mean of 4 independent experiments $( \pm S D)$. p-values (Student $t$-test): $* *<0,01 ; * * *<0,001$. D. Experimental design to assess SUMOylated PML requirement for HIRA accumulation to PML NBs (top). MEFs Pml-/- cells were transduced with Doxinducible lentiviral vectors encoding for Myc-tagged WT or 3K non-SUMOylable PML proteins. Cells were then treated with murine type I IFN $\alpha$ and HIRA localization was observed by fluorescence microscopy. Myc-PML proteins expression was verified by western blot analysis (bottom) of PML from total cellular extracts of MEFs cells describe above. HIRA proteins level was also verified. Actin is a loading control. E. (left) Fluorescence microscopy visualization of HIRA (green) and Myc-PML (red) on MEFs Pml /- cells rescued with Myc-tagged WT (top) or 3K (bottom) PML proteins through 
doxycycline treatment at $100 \mathrm{nM}$ for $24 \mathrm{~h}$. Cells were at the same time treated with murine IFN $\alpha$ at $1000 \mathrm{U} / \mathrm{mL}$. Cell nuclei are visualized by DAPI staining (grey). Scale bars represent $10 \mu \mathrm{m}$. (right) Histogram shows quantitative analysis of cells with HIRA localization at rescued WT or 3K PML NBs. Numbers represent the mean of 3 independent experiments $\left( \pm S D\right.$ ). p-value (Student t-test): ${ }^{* * * *}<0,0001$. F. (left) Schematic representation of the localization of the mutations on putative SIM motifs on HIRA protein. Fluorescence microscopy visualization of HIRA-HA (green) and PML (red) in BJ cells stably transduced with HIRA-HA WT or HIRA-HA mSIM2 mutant and treated with IFN $\beta$ at 1000U/mL for 24h. (right) Graphics show HA signal intensity of each pixel delimitated within the nuclei in a 3D-surface plot. Higher expression signal appears in yellow to white colors. Histogram shows quantitative analysis of cells with HIRA-HA localization in PML NBs. Numbers represent the mean of 3 independent experiments $( \pm S D)$. p-value (Student $t-$ test): ${ }^{* *}<0,01$.

\section{Figure 4. HIRA accumulation in PML NBs depends on the availability of a pool of soluble H3.3-H4 dimers.}

A. (left) Fluorescence microscopy visualization of HIRA (green) and PML (red) in BJ cells treated with a control siRNA targeting luciferase (siLuc) or with an siRNA against DAXX (siDAXX) for $48 \mathrm{~h}$. Ruxolitinib (Ruxo) was added at $2 \mu \mathrm{M}$ in the last $24 \mathrm{~h}$. Cell nuclei are visualized by DAPI staining (grey). Scale bars represent $10 \mu \mathrm{m}$. (right) Histogram shows quantitative analysis of cells with HIRA localization at PML NBs. p-values (Student t-test): $*<0,05$; ns: non significant. Numbers represent the mean of 3 independent experiments $( \pm S D)$. B. Histogram shows quantitative analysis of PML protein levels from western blot analysis presented in Sup. Figure 3C. p-values (Student t-test): ns: non significant. Numbers represent the mean of 3 independent experiments $( \pm S D)$. C. (left) Fluorescence microscopy visualization of HIRA (green) and H3.3-HA (red) in BJ eH3.3i cells treated with doxycyclin (Dox) and IFN $\beta$ for 24h. Arrowheads indicate nuclei with high levels of nucleoplasmic H3.3-HA preventing HIRA accumulation in PML NBs despite IFN $\beta$ treatment. Scale bars represent $10 \mu \mathrm{m}$. (right) Histogram shows quantitative analysis of cells with HIRA localization at PML NBs in BJ eH3.3i treated with Dox and IFN $\beta$ as indicated for $24 \mathrm{~h}$. p-values (Student t-test): ${ }^{*}<0,05 ;{ }^{* *}<0,01$; ns: non significant. Numbers represent the mean of 3 independent experiments $( \pm S D)$. D. Fluorescence microscopy visualization of HIRA (green) and H3.3-HA (red) in BJ eH3.3i cells treated with doxycyclin and with or without IFN $\beta$ for $24 \mathrm{~h}$. High exposure indicates a lane where H3.3-HA signal was specifically increased in order to show H3.3-HA localization in PML NBs without saturating the signal in cells with higher expression. Scale bars represent $10 \mu \mathrm{m}$. E. Quantification of nuclear H3.3-HA intensity levels in BJ eH3.3i cells treated as in C. Mean H3.3-HA intensity levels were calculated on a pool of $n=121$ nuclei from 3 independent experiments (total). Nuclei were then separated on basis of accumulation of HIRA in PML NBs (nuclei with HIRA in PML NBs, $n=58$ ) or without it (nuclei with no HIRA in PML NBs, $\mathrm{n}=63$ ) and mean H3.3-HA intensity was plotted for each category. Bars represent median with interquartile range. p-values (Mann-Whitney u-test): $* * * *<0,0001$. F. Fluorescence microscopy visualization of HIRA (green) and H3.3-HA (red) in IMR90 eH3.3i cells treated as in C. Scale bars represent $10 \mu \mathrm{m}$. Arrows indicate nuclei showing accumulation of HIRA in PML NBs together with H3.3-HA, while arrowheads indicate nuclei with high levels of nucleoplasmic H3.3-HA preventing HIRA accumulation in PML NBs despite IFN $\beta$ treatment. 


\section{Figure 5. Transcription inhibition impairs IFN-induced HIRA accumulation in PML NBs.}

A,C. Fluorescence microscopy visualization of HIRA (green) and PML (red) in BJ cells with different treatments. Cell nuclei are visualized by DAPI staining (grey). Scale bars represent $10 \mu \mathrm{m}$. Histograms show quantitative analysis of cells with HIRA localization at PML NBs. p-values (Student t-test): ${ }^{*}<0,05 ;{ }^{* *}<0,01 ;{ }^{* * *}<0,001 ;$ ns: non significant. A. Images (left) and histogram (right) for BJ cells treated with IFN $\beta$ at $1000 \mathrm{U} / \mathrm{mL}$ for $24 \mathrm{~h}$ and DRB at $50 \mathrm{mM}$ for the last $6 \mathrm{~h}$. Numbers on the histogram represent the mean of 3 independent experiments $( \pm S D)$. B. Western blot visualization of PML and HIRA from total cellular extracts of BJ cells treated as in A. Tubulin is a loading control. C. Images (left) and histogram (right) for BJ cells treated with IFN $\beta$ at $1000 \mathrm{U} / \mathrm{mL}$ for $24 \mathrm{~h}$. $\alpha$ amanitin ( $\alpha$-Ama) was added one hour before IFN $\beta$ treatment and left for $25 \mathrm{~h}$. Numbers on the histogram represent the mean of 3 independent experiments $( \pm S D)$. D. Western blot visualization of PML and HIRA from total cellular extracts of BJ cells treated as in C. Tubulin is a loading control.

Figure 6. HIRA and PML depletions impair H3.3 enrichment at distal regions of ISGs. A. (top) Schematic representation of MX1, OAS1 and ISG54 gene loci. Localization of primers is marked in color: red, green and blue for primers localized in the Transcription Start Site (TSS-, mid or Transcription End Site (TES) region respectively. Black boxes represent exons and lines represent introns. (bottom) Histogram shows H3.3 enrichment fold change obtained through ChIP experiments on BJ cells treated or not with IFN $\beta$ at $1000 \mathrm{U} / \mathrm{mL}$ for $24 \mathrm{~h}$. Rationalization was performed on H3.3 enrichment in untreated cells. qPCR was performed on MX1,OAS1 and ISG54 ISGs TSS, mid and TES regions and on one enhancer region on chromosome 1 (Enh1). Numbers represent the mean of 3 independent experiments ( \pm SD). p-value (Student t-test): ${ }^{* *}<0,01 ; \quad{ }^{* * *}<0,001$; $* * * *<0,0001$. B. ChIP-Seq profile of H3.3 enrichment over 49 core ISGs (38) ranging from $-2.0 \mathrm{~kb}$ to $2.0 \mathrm{~kb}$ downstream and upstream of the gene bodies in BJ cells treated as in A. C. ChIP-Seq profile of H3.3 enrichment over 49 coding non-ISGs equal in size to core ISGs (38), ranging from $-2.0 \mathrm{~kb}$ to $2.0 \mathrm{~kb}$ downstream and upstream of the gene bodies (regions from TSS to $+1000 \mathrm{bp}$ and from -1000 to TES being kept unscaled) in BJ cells treated as in A. D. Gene Ontology analysis on genes showing the highest differential H3.3 enrichment ( $\log 2$ (Fold Change) $>5$ ) in the TES $+/-0.5 \mathrm{~kb}$ region between IFN $\beta$ treated and not treated conditions. E. (left) Western blot analysis of HIRA and PML from total cellular extracts of BJ cells treated with the indicated siRNAs for $72 \mathrm{~h}$ and with IFN $\beta$ at $1000 \mathrm{U} / \mathrm{mL}$ for the last $24 \mathrm{~h}$ of siRNAs treatment. Tubulin is a loading control. (right) Histogram shows H3.3 enrichment obtained through ChIP experiments on BJ cells treated as on the left panel. Rationalization was performed on H3.3 enrichment in siLuc +IFN treated cells. qPCR was performed on MX1 mid and TES regions, OAS1 TES region and ISG54 mid region. Numbers represent the mean of 4 independent experiments $( \pm S D)$. p-value (Student $t$-test): ${ }^{*}<0,05$; $* *<0,01 ; * * * *<0,0001$; ns: non significant. F. ChIP-Seq profile of H3.3 enrichment over 49 core ISGs (38) ranging from $-0.5 \mathrm{~kb}$ to $0.5 \mathrm{~kb}$ downstream and upstream of the TES in BJ cells treated as in E. G. Representative genome browser snapshots of the H3.3 enrichment across the TES region of 2 ISGS : STAT1 and GTP cyclohydrolase 1 (GCH1). Shown are the log2 fold changes of H3.3 enrichment in siLuc + IFN/siLuc NT cells (blue), siHIRA+IFN/siLuc+IFN treated cells (green) and siPML+IFN/siLuc+IFN treated cells (orange). 
Figure 7. Hypothetical model describing the interplay between PML NBs and HIRA for H3.3 deposition on transcriptionally active ISGs.

In a normal situation, a flow of HIRA complex is driven into PML NBs by transcriptional activity: (1) HIRA enters PML NBs in order to retrieve H3.3-H4 dimers brought by DAXX. (2) HIRA then leaves PML NBs to deposit H3.3 on transcriptionally active genes. In absence of DAXX, HIRA accumulates in PML NBs while waiting for H3.3-H4 dimers. Upon IFN-I treatment, the residence time of HIRA may increase due to the high demand for H3.3 transcriptional-coupled deposition leading to accumulation of HIRA in PML NBs, before HIRA-mediated H3.3 deposition on ISGs. SUMO/SIM interactions participate in the localization of HIRA in PML NBs. (3) Upon transcriptional inhibition, HIRA does not accumulate in PML NBs (3). Presence of high soluble pool of H3.3-H4 in the nucleoplasm also prevents HIRA accumulation in PML NBs (4). 
Figure 1
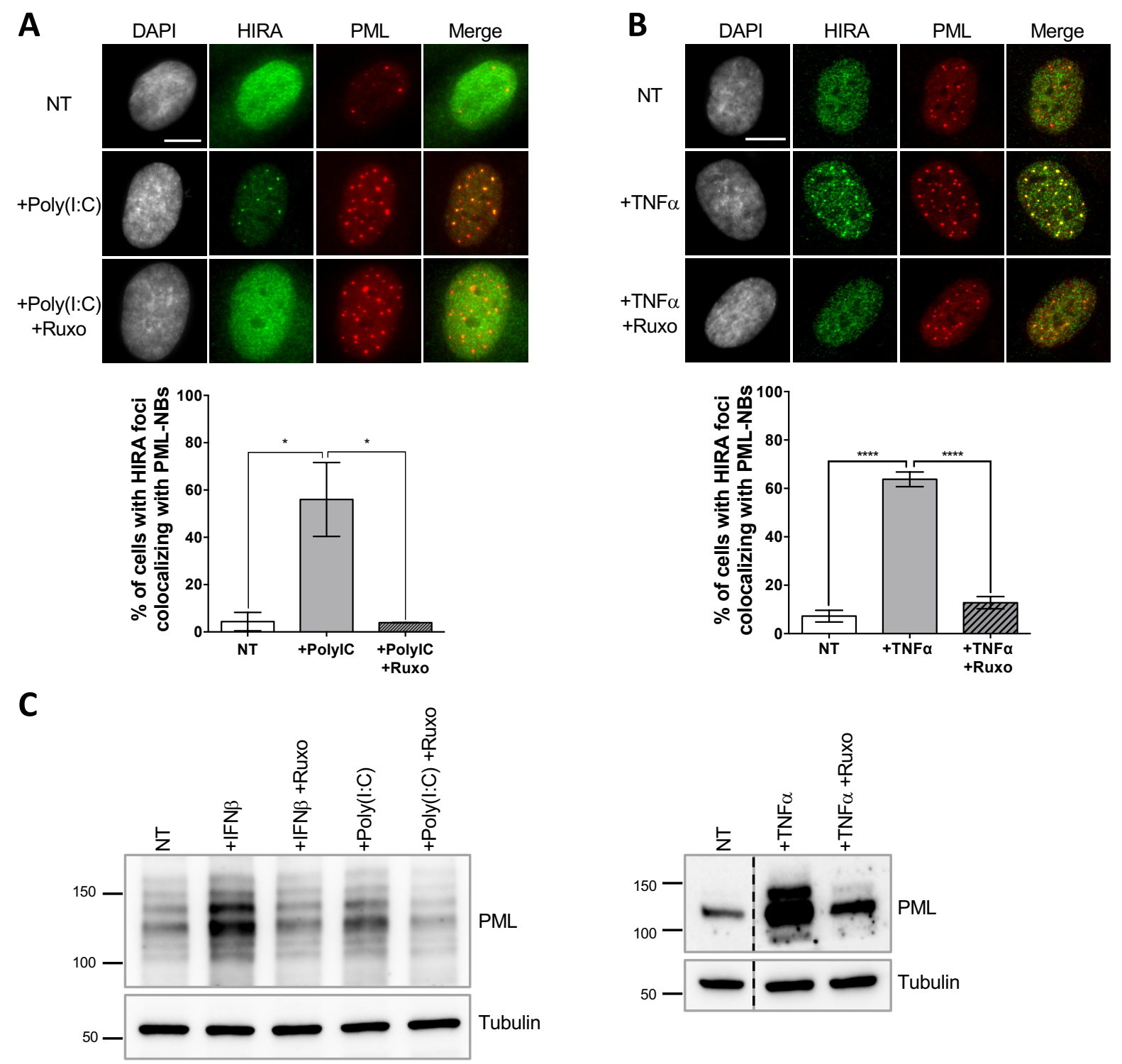
Figure 2

A

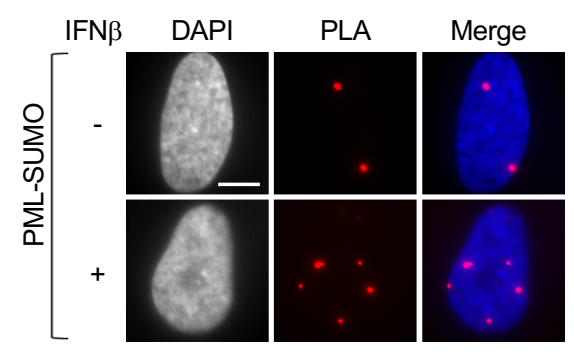

B
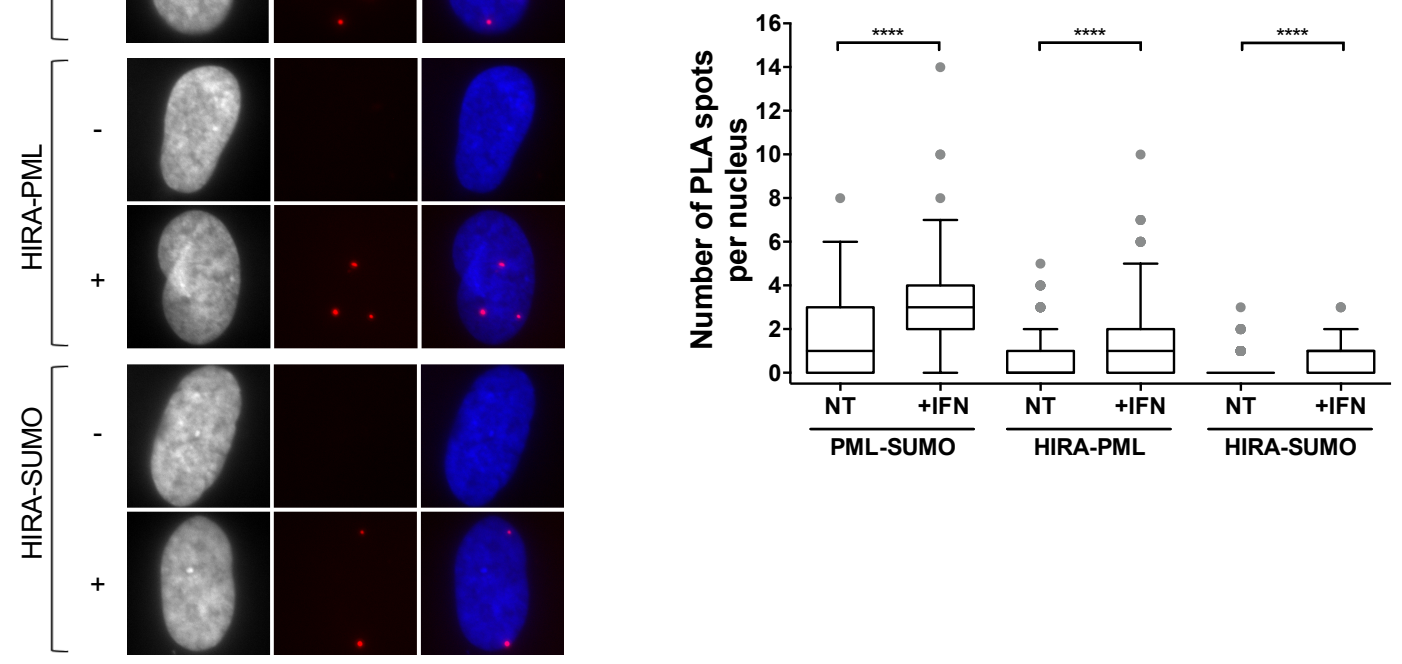

C

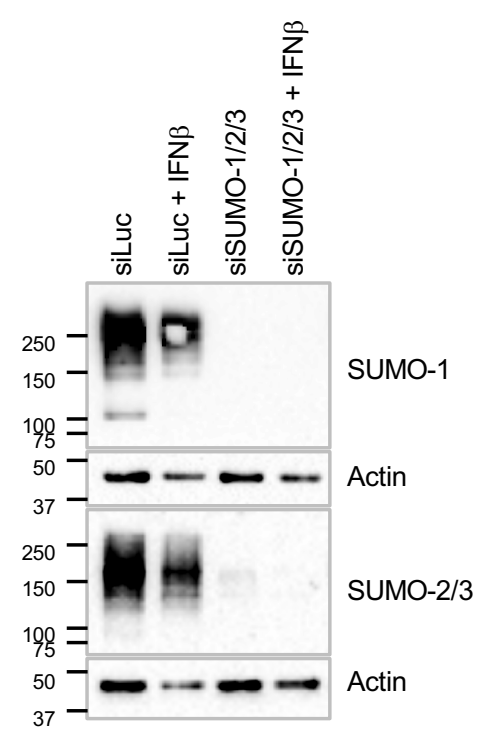

D
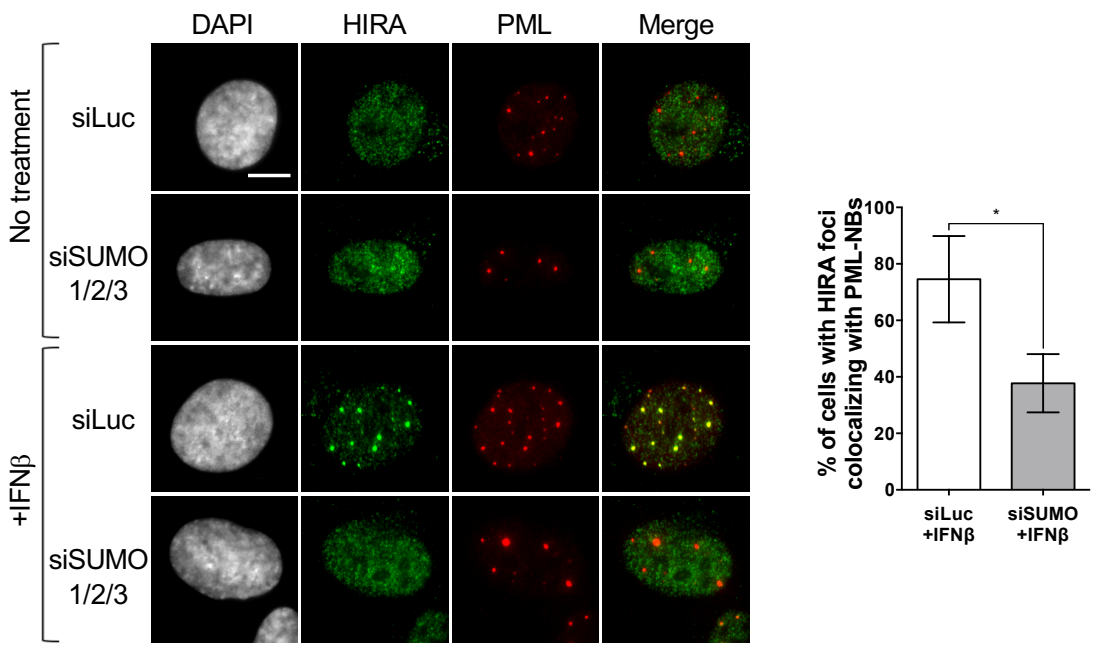


\section{Figure 3}

A encoding
SUMO-specific affimers

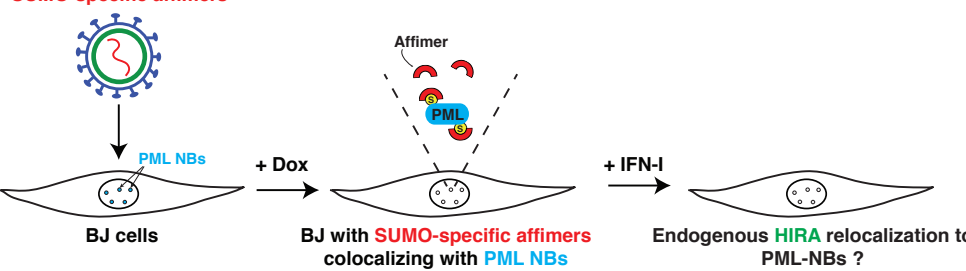

B

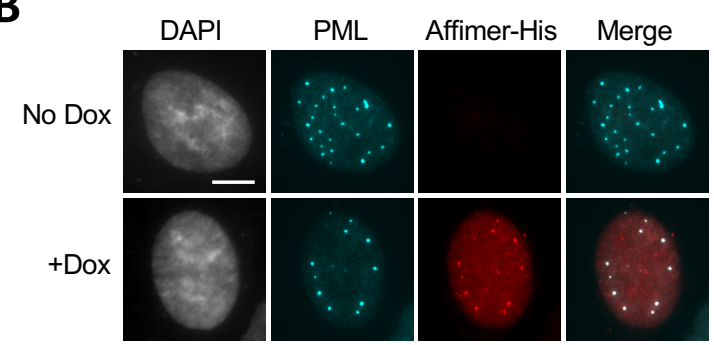

C
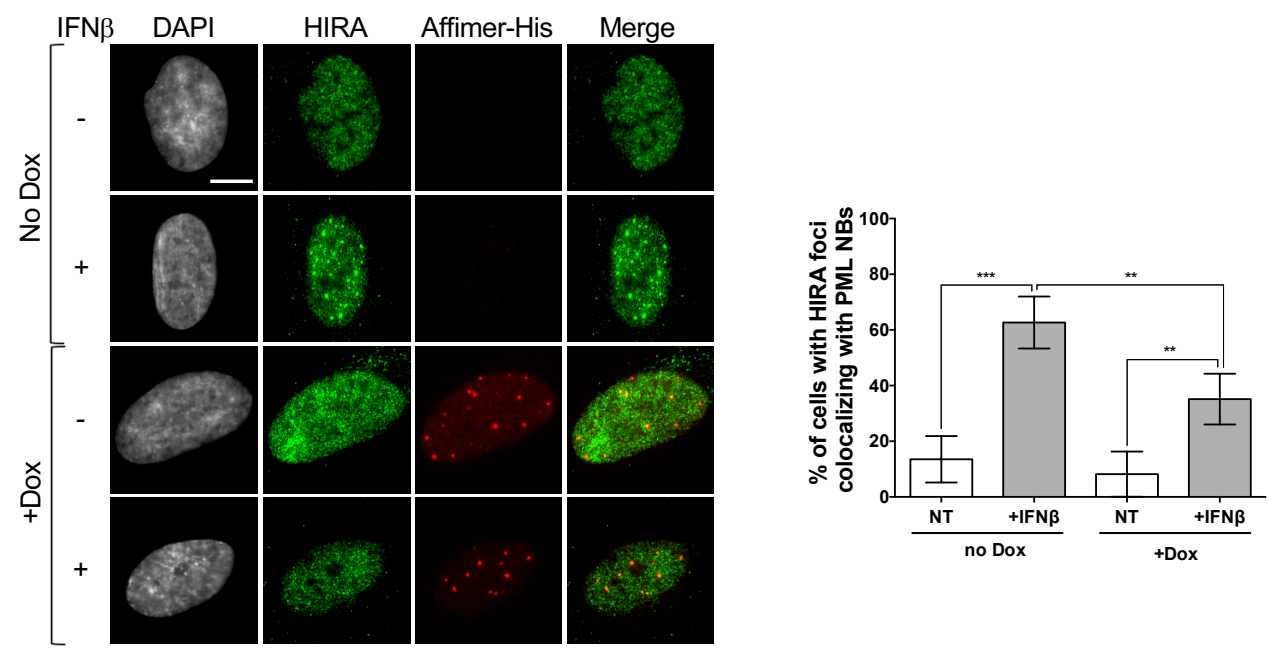

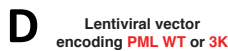

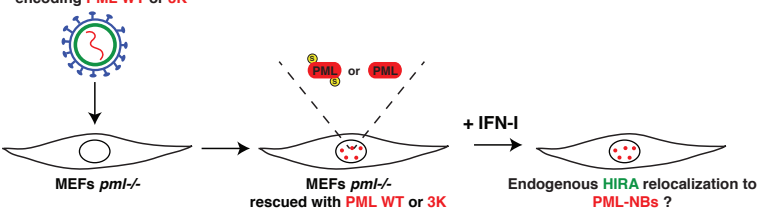

E

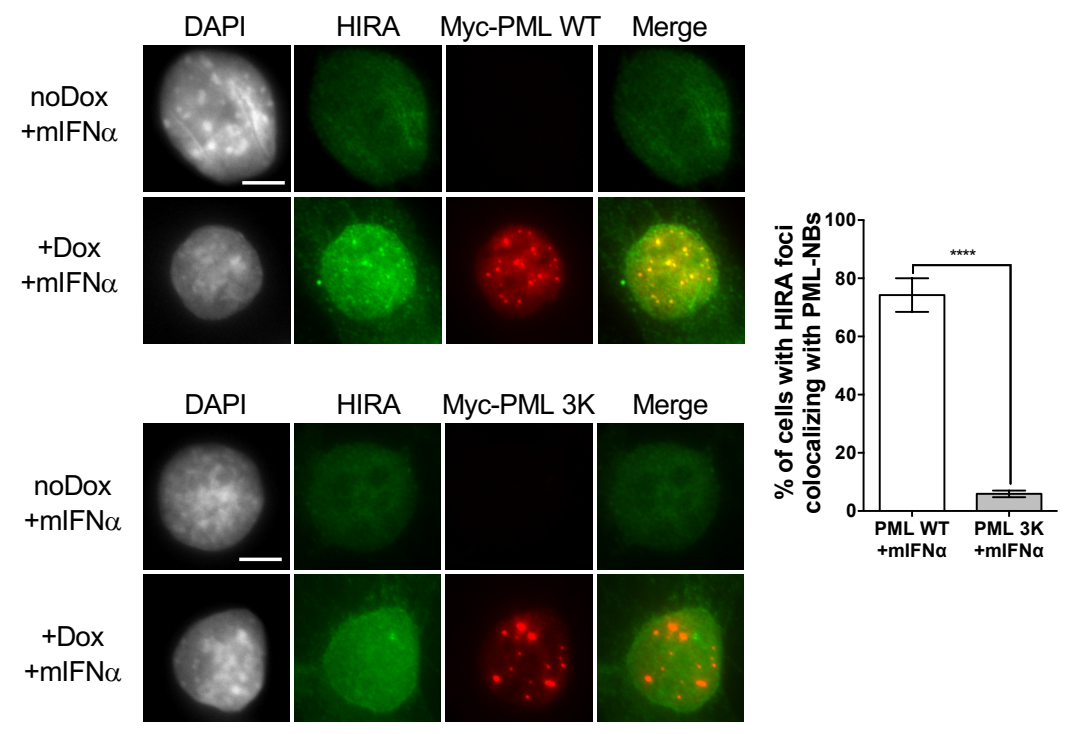

$\mathbf{F}$
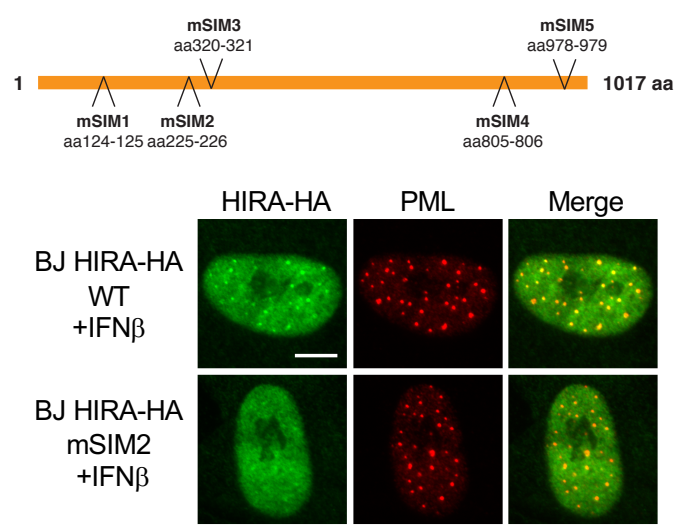

BJ HIRA-HA WT +IFN $\beta$

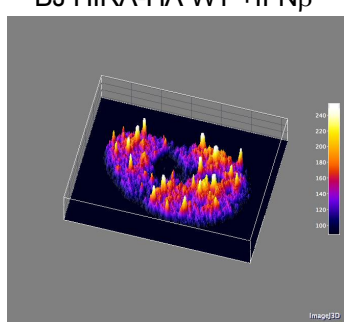

BJ HIRA-HA mSIM2 +IFN

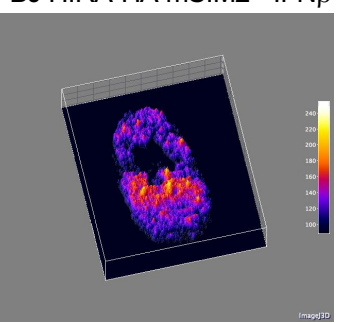

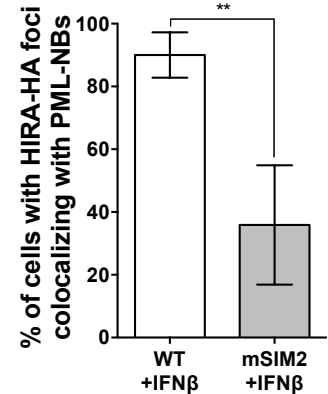


Figure 4

A
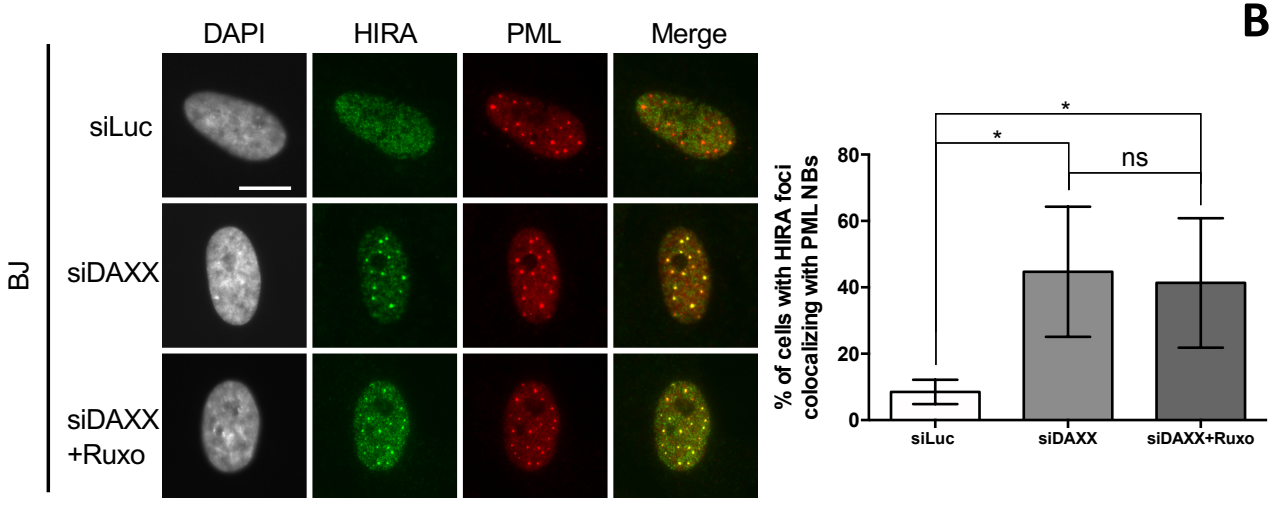

B

C
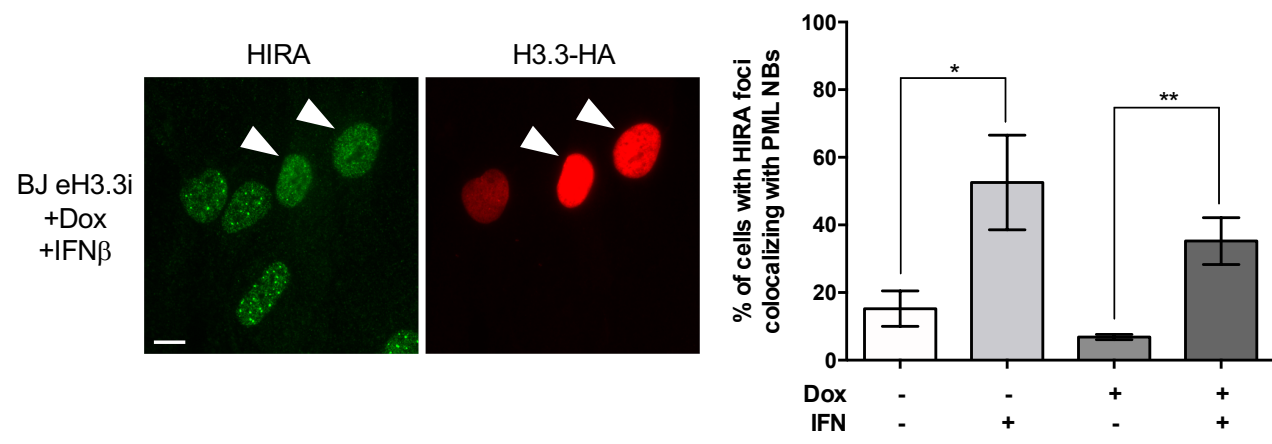

D

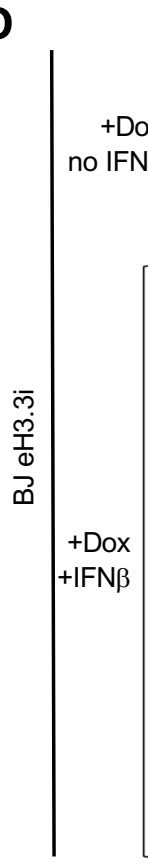

HIRA

H3.3-HA

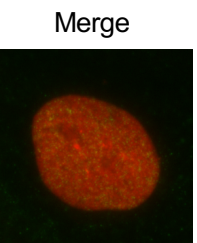

Exposure

E
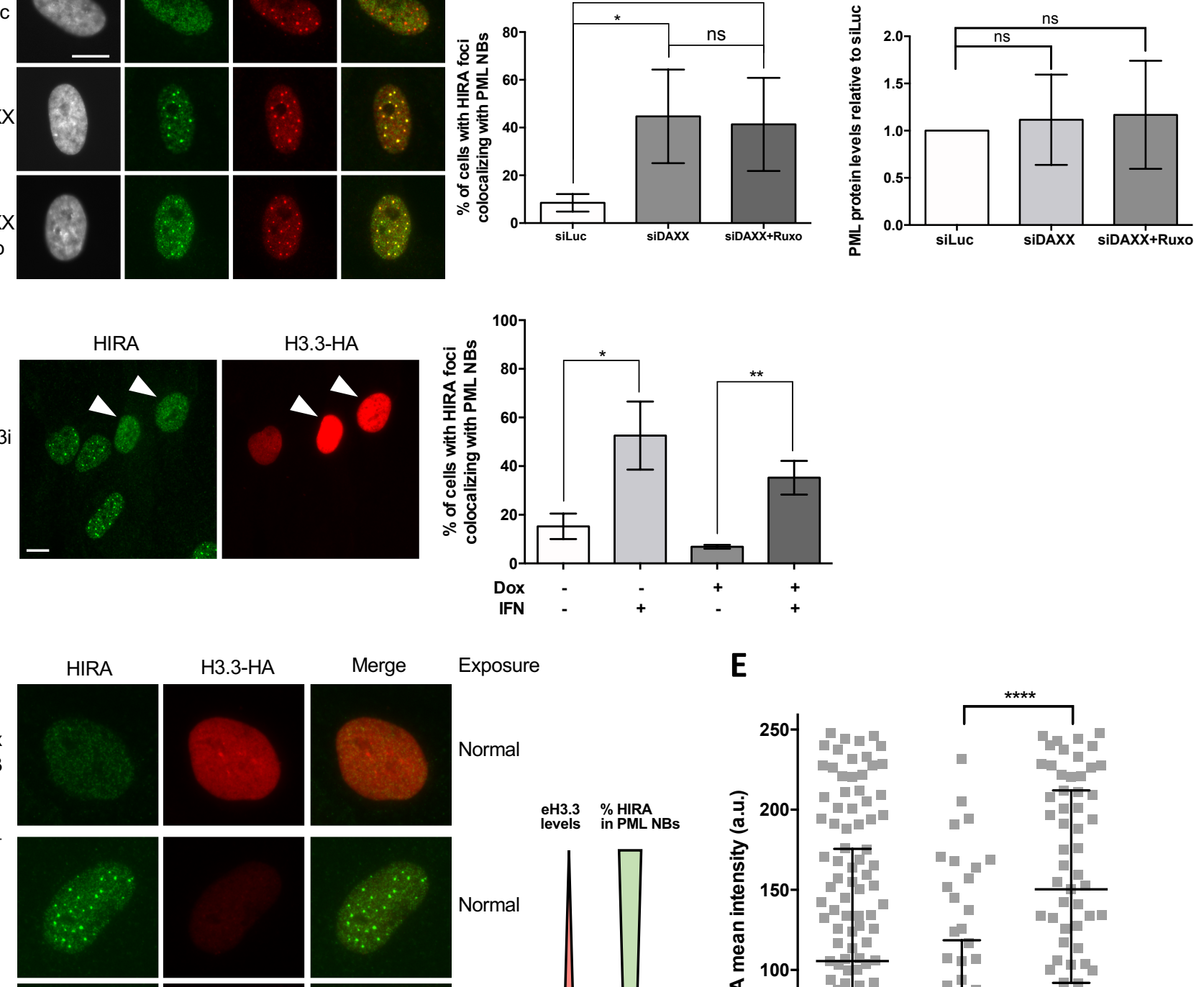

Normal

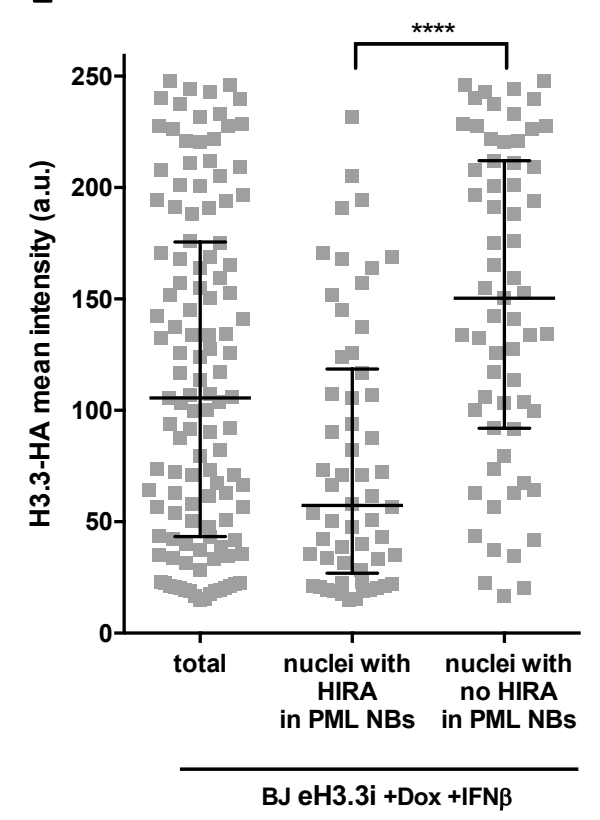

Normal

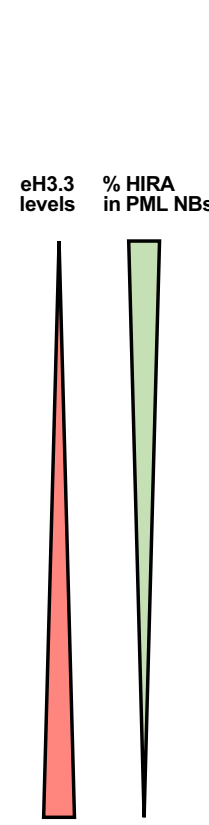

F

DAPI

HIRA

H3.3-HA

Merge
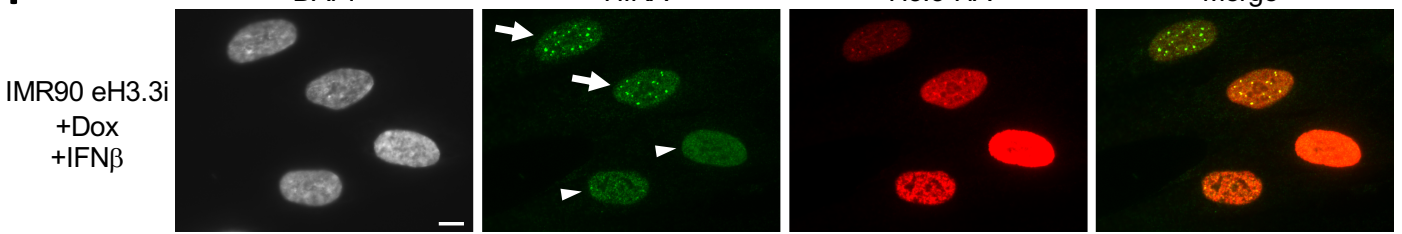


\section{Figure 5}

A

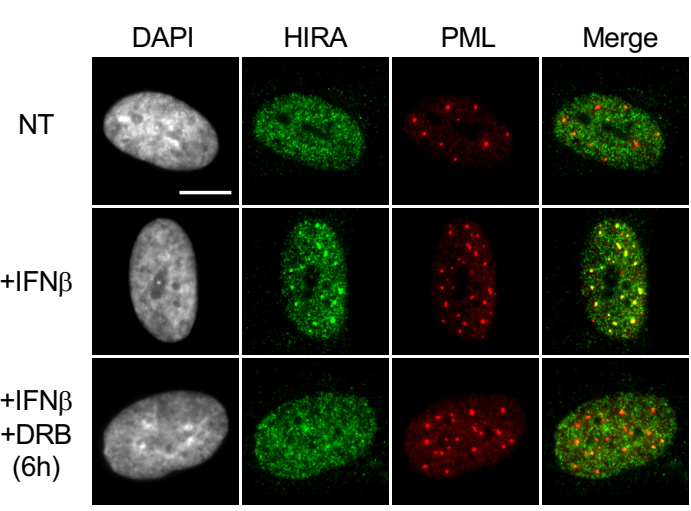

C

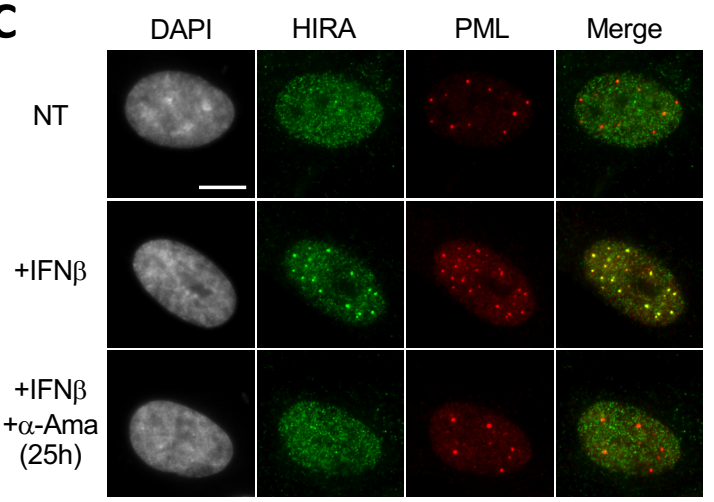

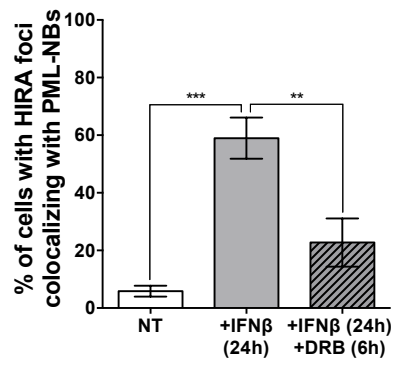

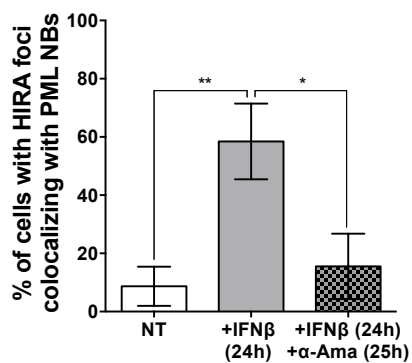

B

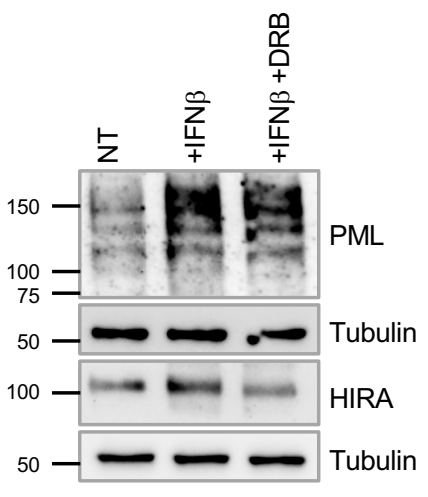

D

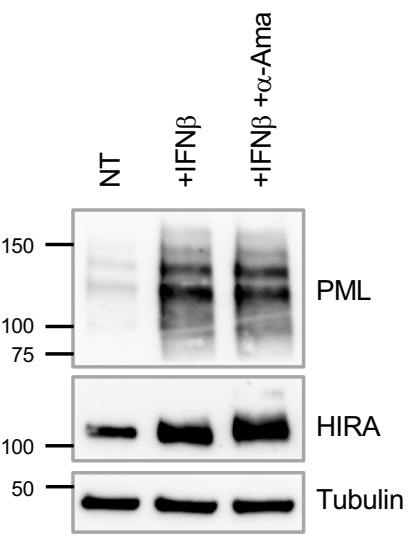


Figure 6

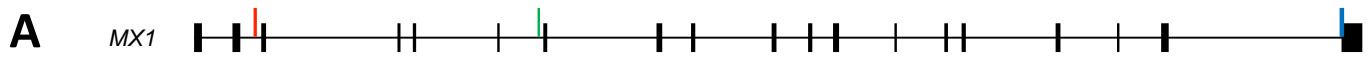

OAS1 $4 \mathbf{1}$

ISG54 4 | 1 (NM_001547.5)
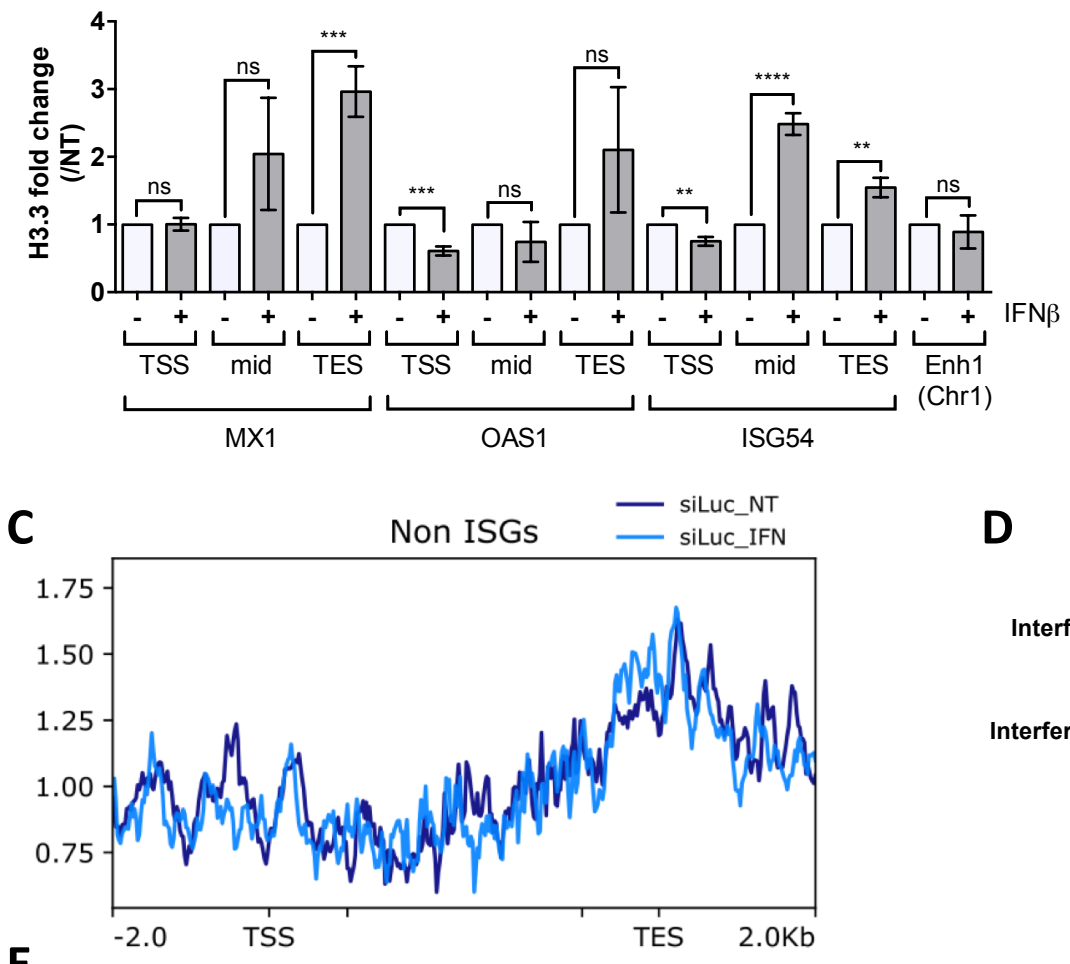

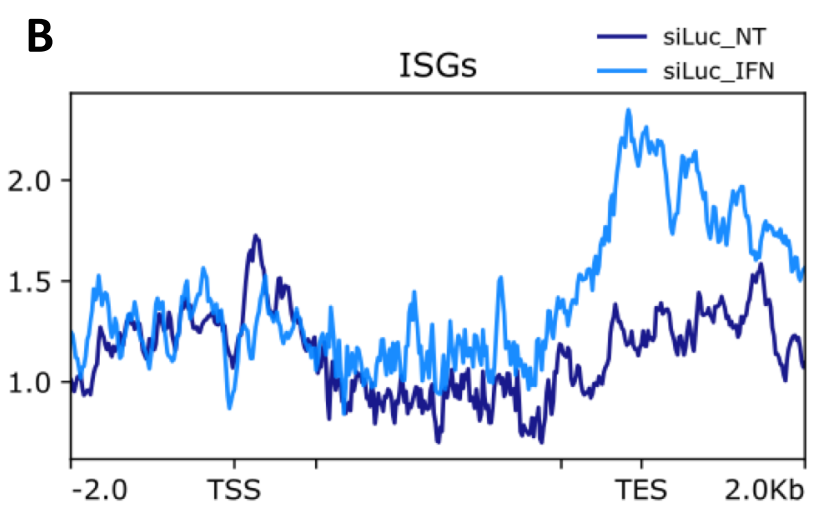

D

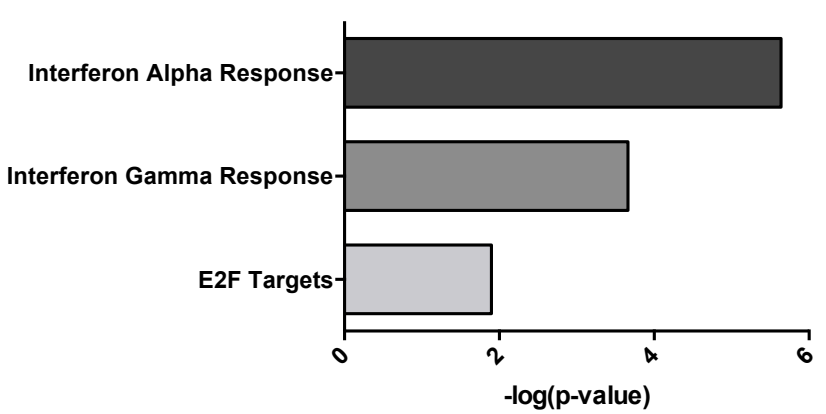

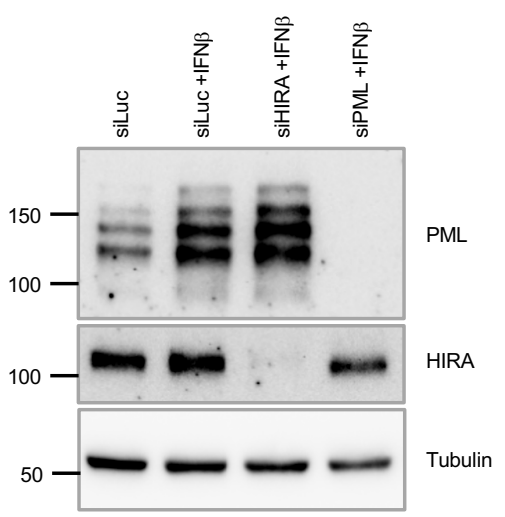

$\mathbf{F}$

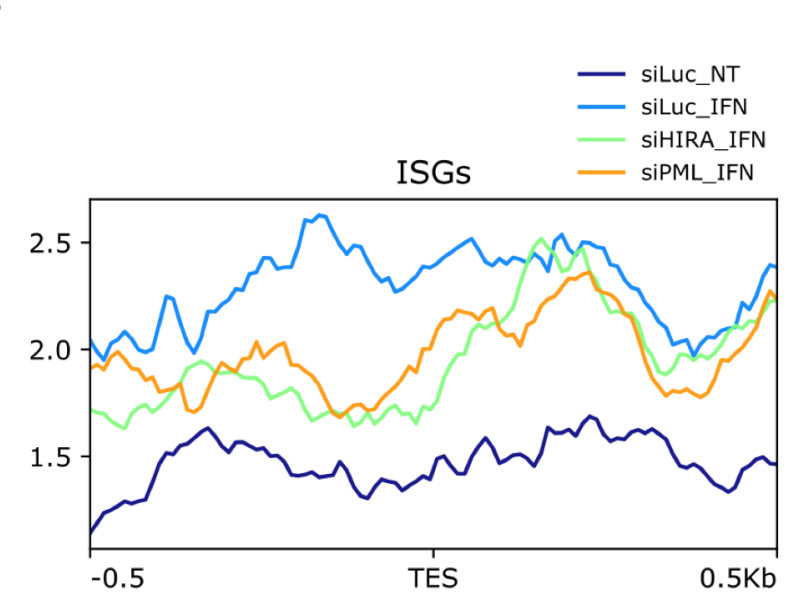

G
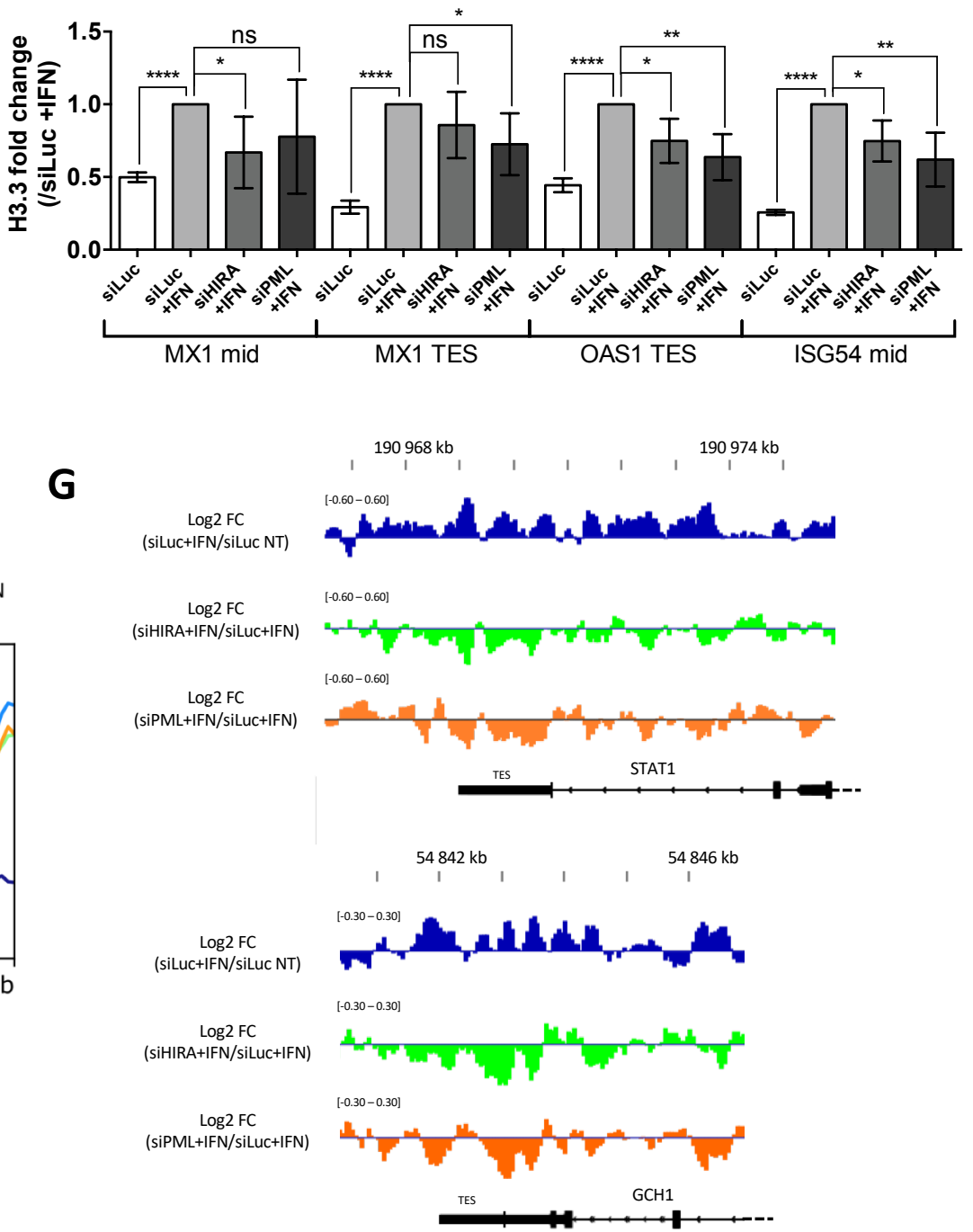
Figure 7

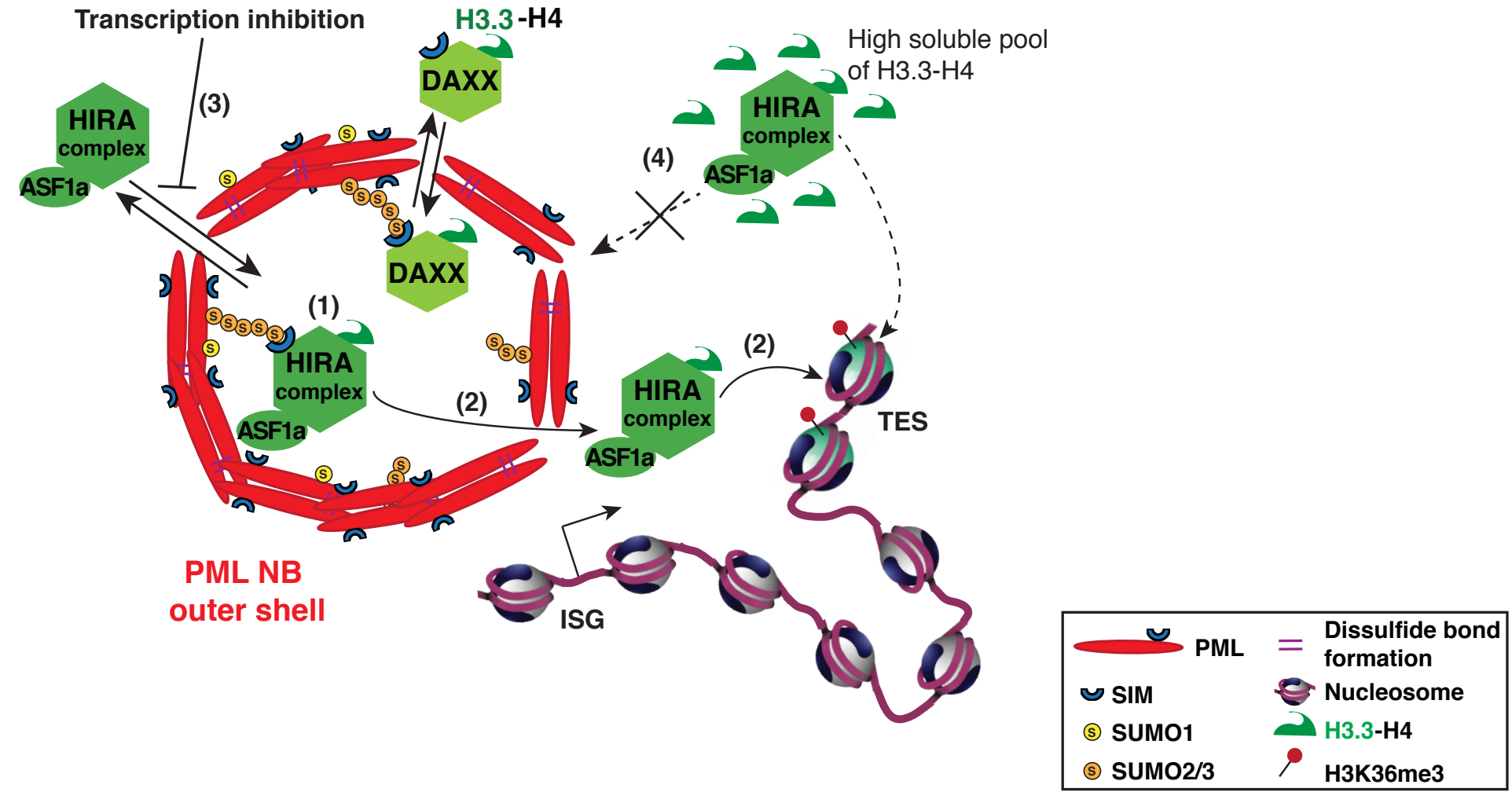

